\title{
Good-bye Scydmaenidae, or why the ant-like stone beetles should become megadiverse Staphylinidae sensu latissimo (Coleoptera)
}

\author{
VASILY V. GREBENNIKOV ${ }^{1,2}$ and AlFrEd F. NEWTON ${ }^{3}$
}

\begin{abstract}
${ }^{1}$ Entomology Research Laboratory, Ottawa Plant and Seed Laboratories, Canadian Food Inspection Agency, K.W. Neatby Bldg., 960 Carling Avenue, Canadian National Collection of Insects, Arachnids and Nematodes, Ottawa, Ontario K1A 0C6, Canada; e-mail: vasily.grebennikov@inspection.gc.ca

${ }^{2}$ Entomology Group, Institut für Spezielle Zoologie und Evolutionsbiologie, Friedrich-Schiller-Universität Jena, Erbertstraße 1, 07743 Jena, Germany

${ }^{3}$ Field Museum of Natural History, 1400 South Lake Shore Drive, Chicago IL 60605-2496, USA; e-mail: anewton@fieldmuseum.org
\end{abstract}

Key words. Coleoptera, Staphylinidae sensu latissimo, Staphylinine Group, Scydmaenidae, taxonomy, phylogeny, classification, morphology, larvae, 18S rDNA, parsimony, Bayesian, neighbour joining

\begin{abstract}
Ant-like stone beetles (Coleoptera: Scydmaenidae) include more than 4,850 described species in about 90 genera maintained as a separate cosmopolitan family since 1815. Recent authors have hypothesised that Scydmaenidae might be rooted deep inside rove-beetles (Staphylinidae). To test this hypothesis we analysed 206 parsimoniously informative larval and adult morphological characters scored for 38 taxa. Strict consensus topologies from the shortest trees in all 12 analyses consistently placed Scydmaenidae as sister to (Steninae + Euaesthetinae) in a monophyletic Staphylinine Group (with or without Oxyporinae). The single fully resolved and most consistently supported topology maintains a monophyletic Staphylinine Group consisting of Oxyporinae + (Megalopsidiinae + (("Scydmaenidae" + (Steninae + Euaesthetinae) $)+($ Leptotyphlinae + (Pseudopsinae + (Paederinae + Staphylininae))))); Solierius lacks larval data and is ambiguously placed within the Group. Eight analyses of variably aligned 18S rDNA data for 93 members of Staphylinoidea under parsimony, neighbour-joining and Bayesian approaches were markedly inconsistent, although partly congruent with the Scydmaenidae + (Steninae + Euaesthetinae) hypothesis. Our results strongly suggest that ant-like stone beetles do not form an independent family, but are morphologically modified members of Staphylinidae and, consequently, should be treated as a 32nd recent subfamily within the megadiverse Staphylinidae sensu latissimo. Formal taxonomic acts are: Scydmaeninae Leach, 1815, status novus (= Scydmaenidae Leach, 1815); Scydmaenitae Leach, 1815, status novus (= Scydmaeninae Leach, 1815); Mastigitae Fleming, 1821, status novus (= Mastiginae Fleming, 1821); Hapsomelitae Poinar \& Brown, 2004, status novus (= Hapsomelinae Poinar \& Brown, 2004). The family Staphylinidae sensu latissimo becomes the largest in Coleoptera and in the whole of the Animal Kingdom, with 55,440 described species (extant plus extinct), thus surpassing Curculionidae with an estimated 51,000 described species.
\end{abstract}

\section{INTRODUCTION}

The beetle family Staphylinidae, or rove beetles, is one of the largest families of beetles and, indeed, of animals, passing the 50,000 described species mark in 2007 (Newton, 2007). The monophyly of the family, and its internal phylogeny and classification, have been the subject of intensifying research in the past three decades. Lawrence \& Newton (1982) summarized the classification at that time and proposed that the 22-odd staphylinid subfamilies recognized then could be organized into four main lineages or informal groups, with several small allied families being probably or possibly related to one or another of these lineages (making Staphylinidae paraphyletic with respect to these other families). The largest such lineage, termed by them the "staphylinine group", included the staphylinid subfamilies Oxyporinae, Megalopsidiinae, Steninae, Euaesthetinae, Leptotyphlinae, Paederinae, Staphylininae "and possibly Scydmaenidae and Silphidae". Subsequent studies by many authors have tested and in some cases supported or refuted their suggestions, e.g., Newton \& Thayer (1995) provided strong phylogenetic evidence that the former families Micropeplidae, Dasy- ceridae and Pselaphidae were nested within the "Omaliine Group" of Lawrence \& Newton (1982), as those authors had suggested, and formally recognized those families as subfamilies of Staphylinidae to resolve the paraphyly of Staphylinidae.

In the case of the Staphylinine Group, such subsequent work has indicated that two staphylinid taxa should be added to it: Pseudopsinae and Solieriinae. Pseudopsinae were redefined by Newton (1982) to include several genera usually placed in Piestinae or Oxytelinae in addition to Pseudopsis Newman, 1834, but at that time he placed this subfamily in the "tachyporine group" (Lawrence \& Newton, 1982). Subsequent discovery and description of pseudopsine larvae and phylogenetic analysis of larval characters have corroborated the monophyly of Pseudopsinae and provided strong evidence for a sister-group relationship of Pseudopsinae to Paederinae + Staphylininae (Grebennikov, 2005). The genus Solierius Bernhauer, 1921, was generally placed in the subfamily Omaliinae until Newton \& Thayer (1992) established a subfamily for it and excluded it from the Omaliine Group, and subsequently (1995) placed it in the Staphylinine 


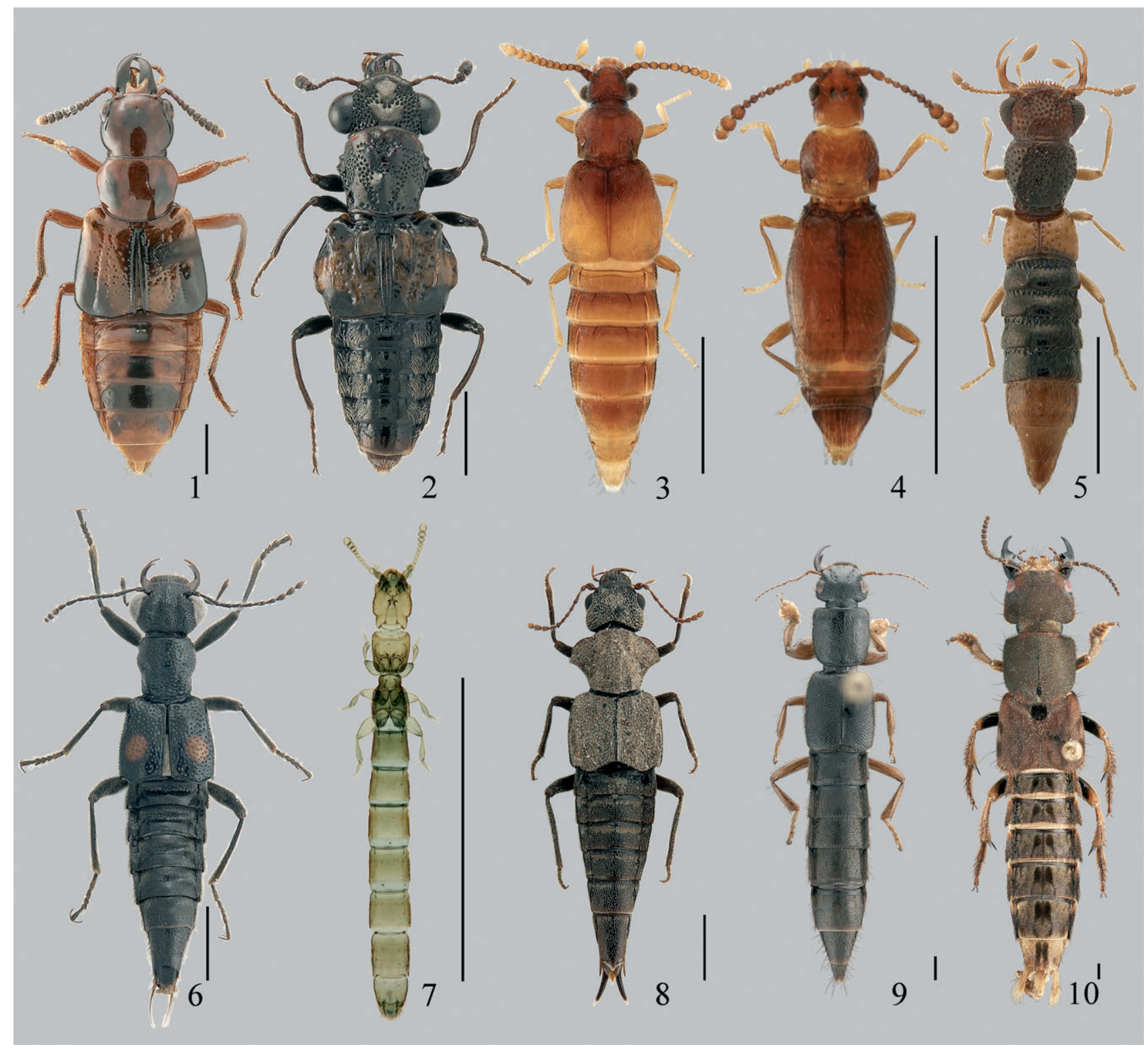

Figs 1-10. Adult dorsal habitus representing each of ten rove-beetle subfamilies belonging to Staphylinine Group. 1 - Oxyporus occipitalis Fauvel, 1864 (Oxyporinae); 2 - Megalopinus sanguinitriguttatus (Scheerpeltz, 1972) (Megalopsidiinae); 3 - Solierius obscurus (Solier, 1849) (Solieriinae); 4 - Veraphis sp. (Scydmaeninae); 5 - Alzadaesthetus furcillatus Saiz, 1972 (Euaesthetinae); 6 - Dianous nitidulus LeConte, 1874 (Steninae); 7 - Eutyphlops sp. (Leptotyphlinae); 8 - Zalobius spinicollis LeConte, 1874 (Pseudopsinae); 9 - Pinophilus latipes Gravenhorst, 1802 (Paederinae); 10 - Platydracus maculosus (Gravenhorst, 1802) (Staphylininae). Scale bar $1 \mathrm{~mm}$.

Group without further analysis. More recent studies involving subsets of the taxa of the Staphylinine Group have provided further support for monophyly of or relationships among some of the included subfamilies based on adult and larval morphology, including monophyly of the largest subfamilies, Staphylininae and Paederinae, and their sister-group relationship (Solodovnikov \& Newton, 2005); monophyly of Euaesthetinae and Steninae and their sister-group relationship (Leschen \& Newton, 2003; Clarke \& Grebennikov, 2009); and, based on larvae only, monophyly of Leptotyphlinae (Grebennikov \& Newton, 2008). The three remaining subfamilies attributed to the Staphylinine Group (Oxyporinae, Megalopsidiinae, Solieriinae) are monogeneric, and monophyly of the two "possible" members (Silphidae and Scydmaenidae) has been supported in various recent studies (including those cited in the following paragraph) and not questioned in recent times.

Several broader studies have sought to determine relationships among many or all of these subfamily- or family-level taxa, in a larger context but with more limited within-group sampling. Hansen (1997), based on adult and limited larval morphology, found weak support for a group including most of the Staphylinine Group subfamilies but excluding Leptotyphlinae and Solieriinae (nested in another clade of Staphylinidae) and Silphidae and Scydmaenidae (placed just outside his Staphylinidae, which also excluded three staphylinid subfamilies). 
TABLE 1. List of 38 terminals included in the phylogenetic analysis of the Staphylinine Group of the rove-beetle subfamilies (Coleoptera: Staphylinidae). Larva of Solierius is unknown and not studied. Subfamilies in bold represent members of the Staphylinine Group.

\begin{tabular}{|c|c|c|c|c|c|c|c|}
\hline Family/subfamily & Genus & Adults & Larvae & Family/subfamily & Genus & Adults & Larvae \\
\hline$\overline{\text { LEIODIDAE }}$ & Neopelatops Jeannel, 1936 & $x$ & $x$ & STENINAE & Stenus Latreille, 1797 & $x$ & $x$ \\
\hline AGYRTIDAE & Necrophilus Latreille, 1829 & $x$ & $x$ & STENINAE & Dianous Leach, 1819 & $x$ & $x$ \\
\hline SILPHINAE & Thanatophilus Leach, 1815 & $x$ & $x$ & EUAESTHETINAE & Euaesthetus Gravenhorst, 1806 & $x$ & $x$ \\
\hline SILPHINAE & Necrodes Leach, 1815 & $x$ & $x$ & EUAESTHETINAE & Edaphus Motschulsky, 1857 & $x$ & $x$ \\
\hline SILPHINAE & Nicrophorus Fabricius, 1775 & $x$ & $x$ & EUAESTHETINAE & Octavius Fauvel, 1873 & $x$ & $x$ \\
\hline APATETICINAE & Nodynus Waterhous, 1876 & $x$ & $x$ & EUAESTHETINAE & Alzadaesthetus Kistner, 1961 & $x$ & $x$ \\
\hline TRIGONURINAE & Trigonurus Mulsant, 1847 & $x$ & $x$ & LEPTOTYPHLINAE & MexLeptotyphlinae & $x$ & $x$ \\
\hline OMALIINAE & Acrolocha Thomson, 1858 & $x$ & $x$ & LEPTOTYPHLINAE & ChiLeptotyphlinae & $x$ & $x$ \\
\hline TACHYPORINAE & Tachinus Gravenhorst, 1802 & $x$ & $x$ & LEPTOTYPHLINAE & AusLeptotyphlinae & $x$ & $x$ \\
\hline PIESTINAE & Siagonium Kirby \& Spence, 1815 & $x$ & $x$ & PSEUDOPSINAE & Zalobius LeConte, 1874 & $x$ & $x$ \\
\hline OXYPORINAE & Oxyporus Fabriciaus, 1775 & $\times$ & $\times$ & PSEUDOPSINAE & Pseudopsis Newman, 1839 & $x$ & $x$ \\
\hline MEGALOPSIDIINAE & Megalopinus Eichelbaum, 1915 & $x$ & $x$ & PSEUDOPSINAE & Nanobius Herman, 1977 & $x$ & $x$ \\
\hline SOLIERIINAE & Solierius Bernhauer, 1921 & $x$ & - & PAEDERINAE & Pinophilus Gravenhorst, 1802 & $x$ & $x$ \\
\hline SCYDMAENINAE & Scydmaenus Latreille, 1802 & $\times$ & $x$ & PAEDERINAE & Achenomorphus Motsch., 1858 & $x$ & $x$ \\
\hline SCYDMAENINAE & Veraphis Casey, 1987 & $\times$ & $x$ & PAEDERINAE & Hyperomma Fauvel, 1878 & $x$ & $x$ \\
\hline SCYDMAENINAE & Cephennodes Reitter, 1884 & $x$ & $x$ & STAPHYLININAE & Arrowinus Bernhauer, 1935 & $x$ & $x$ \\
\hline SCYDMAENINAE & Palaeostigus Newton, 1982 & $x$ & $\times$ & STAPHYLININAE & Xanthopygus Kraatz, 1857 & $x$ & $x$ \\
\hline SCYDMAENINAE & Stenichnus Thomson, 1859 & $x$ & $x$ & STAPHYLININAE & Nudobius Thomson, 1860 & $x$ & $x$ \\
\hline SCYDMAENINAE & Euconnus Thomson, 1859 & $x$ & $x$ & STAPHYLININAE & Platydracus Thomson, 1858 & $x$ & $x$ \\
\hline
\end{tabular}

Beutel \& Molenda (1997), based on larval morphology only, found a monophyletic Staphylinine Group including Scydmaenidae, and also including Pselaphinae, but excluding Silphidae as a sister group to all Staphylinidae. Caterino et al. (2005), using 18S rDNA and a morphological data set extracted from Hansen (1997), did not get strong resolution of staphylinid taxa but Silphidae and Scydmaenidae were mixed in with a group including most Staphylinidae. Beutel \& Leschen (2005), based on adult and larval morphology, also found Staphylinidae, Silphidae and Scydmaenidae consistently grouped as a monophyletic unit in partitioned and combined analyses, but did not attempt to resolve relationships within Staphylinidae. Finally, two recent strictly molecular analyses did not support a close relationship of these three groups: Korte et al. (2004), based on 18S and 28S rDNA of a limited number of taxa, found support for a monophyletic Staphylinidae, and for Scydmaenidae as sister group to Ptiliidae, with Silphidae weakly related to Hydraenidae or Hydrophilidae, while Hunt et al. (2007), based primarily on 18S rDNA, included seven subfamilies of the Staphylinine Group + Silphidae (as Silphinae) scattered within a monophyletic Staphylinidae, but Scydmaenidae well removed from these and nearer the base of Polyphaga as sister group to Histeroidea.

The purpose of the current study is to provide a new phylogenetic analysis based on a robust sample of all subfamily- and family-level taxa recently suggested as members of the Staphylinine Group, based mainly on adult and larval morphology but supplemented with inclusion of $18 \mathrm{~S}$ rDNA molecular data available for a subset of taxa, with the intention of evaluating the monophyly of the Staphylinine Group and the relationships among the included subfamilies. We focus especially on two groups that have not been included in the more detailed recent studies within the Staphylinine Group mentioned in the second paragraph above: Solieriinae, suggested but not yet demonstrated as a member of the group, and Scydmaenidae, whose placement has varied wildly in recent studies that have included it. Scydmaenids have been universally maintained as a distinct beetle family since 1815 , and placed near other families of what is now the superfamily Staphylinoidea, but have long been shadowed by disagreements over possible relationships to other staphylinoid families. As reviewed in detail by Newton \& Thayer (1995) and Newton \& Franz (1998), this large group of more than 4,850 species placed in about 90 genera and three subfamilies has at various times been considered related to the family Leiodidae and to various groups now included within Staphylinidae, including Pselaphinae, Scaphidiinae and the Staphylinine Group of subfamilies. The broader phylogenetic studies cited in the previous paragraph, and some recent phylogenetic studies of specific groups, have provided no suggestion of a relationship of scydmaenids to Leiodidae (Newton, 1998), Pselaphinae (Newton \& Thayer, 1995), or Scaphidiinae (Leschen \& Löbl, 1995), and the suggested possible relationship to the Staphylinine Group is addressed here.

\section{MATERIAL AND METHODS}

\section{Project design, choice of taxa, outgroup, and data sources for analyses}

Representatives of all rove-beetle subfamilies currently assigned to the Staphylinine Group (Oxyporinae, Megalopsidiinae, Solieriinae, Steninae, Euaesthetinae, Leptotyphlinae, Pseudopsinae, Paederinae, Staphylininae; see Thayer, 2005) were included in the analysis (Table 1). We also included representa- 
tives of Silphidae and Scydmaenidae, two taxa forming a clade with the family Staphylinidae (Beutel \& Leschen, 2005) and conventionally treated as independent families. Both "families", however, were suspected to be a part of the Staphylinine Group of subfamilies (Lawrence \& Newton, 1982), which implies their origin within the rove beetle radiation and, therefore, not deserving their current "family" status. Whenever possible, the morphological matrix included three or more representatives from different genera of each in-group family/subfamily, thus allowing a partial test of their monophyly. Exceptions to this rule were Steninae containing only two genera (both included), monogeneric Oxyporinae and Megalopsidiinae (each genus included), and monogeneric Solieriinae, for which the larvae are still unknown and, therefore, not scored in the larval matrix. In order to rigorously test monophyly of the Staphylinine Group, we included representatives of some rove-beetle subfamilies maintained outside of the Staphylinine Group (Thayer, 2005), such as Omaliinae, Tachyporinae, Piestinae, Apateticinae and Trigonurinae (Table 1). To test monophyly of the in-group clades, we included representatives of the families Leiodidae and Agyrtidae, which belong to a sister-group of Staphylinidae + Silphidae + Scydmaenidae (Beutel \& Leschen, 2005). All obtained trees were rooted at Neopelatops Jeannel, 1936 (Leiodidae).

This project was originally planned to test monophyly of the Staphylinine Group of rove-beetle subfamilies using newly scored larval and adult morphological characters for as many taxa as realistically possible. As our work progressed we found a stream of publications addressing, or touching upon, phylogeny of our target group using genomic data, thus increasing the number of available relevant sequences. Thus we decided to compare our morphology-based phylogenetic hypotheses with the results obtained from the $18 \mathrm{~S}$ rDNA nuclear gene, which arguably is the most widely sequenced gene across the order. This decision was prompted by the recent findings by Hunt et al. (2007), which increased the number of relevant 18 S sequences in GenBank from 53 to 88 taxa (sequences for Silphidae, Ptiliidae, Hydraenidae, Leiodidae, Agyrtidae and Staphylinidae including Scydmaeninae; from this point on we consistently use the subfamily name Scydmaeninae status novus for the traditional "family" of ant-like stone beetles). No attempt was made to merge the morphological and DNA data into a single matrix because of incompatibility of terminals. For the analysis, we employed the 18S DNA sequences for all 88 taxa currently available from GenBank (March 2008), supplemented with five new sequences prepared for this project aimed at introducing previously unrepresented rove-beetle subfamilies (Apateticinae, Leptotyphlinae; for the latter subfamily a specimen of an undescribed Australian genus and species was sequenced; referred to as "Australian genus" in Grebennikov \& Newton, 2008), or sampling more densely the Staphylinine Group (Steninae, Euaesthetinae). GenBank accession numbers for all 93 sequences are listed in Figs 12, 13.

\section{Sources of specimens, their identification, preparation and illustrations}

Lists of larval and adult specimens used in this work and their label data are in Appendix 2 and 3, respectively. Most specimens studied originated from the collection of the Division of Insects, Field Museum of Natural History (FMNH, Chicago); a few larval specimens were from the Canadian National Collection of Insects, Arachnids and Nematodes (CNC, Ottawa). Identifications were done by A. Newton. In most cases larvae were not reared from eggs in a laboratory, but collected in the field and identified using a combination of two main factors: (1) repeated association records with the presumably conspecific adults and (2) underlying knowledge on larval morphology of Staphylinoidea, their distribution, biology, and habitat preferences. Preparation of the adult and larval specimens for morphological study included macerating and clearing non-sclerotized tissue in hot $10 \%$ solution of $\mathrm{KOH}$ and, for some specimens, subsequent staining with chlorazole black. Specimens were mounted in Euparal on microscope slides and studied under dissecting and compound microscopes. Some adult specimens were partly disarticulated, allowing for free manipulation and rotation of the body parts, and stored in glycerol on microscope slides. Photo images were taken with a Microptics ML Macro XLT digital system at Division of Insects, FMNH. Line drawings were prepared using a camera lucida from slide-mounted larvae.

\section{DNA extraction, amplification, alignment, and preparation of DNA matrix}

DNA was extracted from 95\% ethanol-preserved specimens using the "DNeasy Protocol for Animal Tissues" (May 2002 edition of the DNeasy Tissue Handbook distributed with Qiagen's DNeasy Tissue Kit, pp. 17-19). Specimens were partially dissected for enhanced proteinase $\mathrm{K}$ digestion but maintaining the integrity of the specimens. Four overlapping fragments of complete $18 \mathrm{~S}$ rDNA were targeted by using the four primer pairs 18S5'-18Sb5.0, 18Sai-18Sb0.5, 18Sa1.0-18Sbi, and 18Sa2.0-18S3'I (Shull et al., 2001). The PCR program used to amplify all four fragments consisted of an initial denaturation at $94^{\circ} \mathrm{C}$ for two min, followed by 39 cycles of $94^{\circ} \mathrm{C}$ for $30 \mathrm{~s}, 50^{\circ} \mathrm{C}$ for $30 \mathrm{~s}$, and $72^{\circ} \mathrm{C}$ for one min; elongation at $72^{\circ} \mathrm{C}$ for five minutes; final hold at $4^{\circ} \mathrm{C}$ until removed from thermocycler. PCR products were cleaned using the QIAquick PCR Purification Kit (Qiagen, Valencia, CA). Automated fluorescent sequencing was performed by the DNA Sequencing Facility at the University of California-Berkeley, using an Applied Biosystems 96 capillary 3730xl DNA Analyzer. Both strands were sequenced for all fragments. Ninety three sequences were assembled from different sources (Figs 12, 13) in Fasta file and were aligned in ClustalX (Thompson et al., 1997) using the default gap opening/gap extension settings (15/6.66). This alignment formed a matrix 2095 character long (including gaps). A second alignment was performed using MAFFT (Multiple Alignment using Fast Fourier Transform) algorithm (Katoh et al., 2005) implemented in MAFFT version 6 (Katoh et al., 2005), with a L-INS-i strategy and default parameters (gap opening penalty 1.53; offset value 0.00 ). The MAFFT alignment had 2130 characters (including gaps). These two matrixes were used for eight subsequent analyses.

\section{Morphological datasets and analysis}

Two hundred and eleven morphological characters were selected for the analysis; their description and state definition are given in Appendix 1. The combined larval and adult morphological matrix included 38 terminals and all 211 characters (Table 3); since the larvae of Solierius are still unknown, it was not scored for the present analysis. Characters 1-89 are of larval morphology; characters 90-211 are of adult morphology. No polymorphic characters were present in the matrix. Five characters $(54,101,176,193$ and 195; marked with "N" in the bottom row of Table 3) are parsimoniously uninformative and were deactivated before analyses. Eleven multi-state characters $(5,6$, $19,20,31,35,98,108,114,117,126,132,133$; marked with "O" in the bottom row of Table 3 ) were analysed as being either ordered (analyses 3, 4, 7, 8, 11, 12; Table 2) or unordered (analyses 1, 2, 5, 6, 9, 10; Table 2); all other multi-state characters were treated as unordered in all analyses.

Each co-author was responsible for scoring one dataset (larval by VVG and adult by AFN), thus minimizing possible bias. The 
TABLE 2. Results of 12 phylogenetic analyses of the Staphylinine Group of rove-beetle subfamilies (Coleoptera: Staphylinidae) (columns 1-12). "Dataset" row indicates three datasets used in the analysis (larvae, adults, and their combination). "Ordered/unordered" row indicates whether multistate characters $(5 ; 6 ; 19 ; 20 ; 31 ; 35 ; 98 ; 108 ; 114 ; 117 ; 126 ; 132 ; 133)$ were ordered or not. "Successive weighting" row indicates whether successive approximation was used for character weighting. Next three rows indicate tree length, consistency index (ci) and retention index (ri) indexes, and the number of the shortest (= most parsimonious) trees obtained. Taxonomic abbreviations used in the left column are: Eua - Euaesthetinae; Lep - Leptotyphlinae; Meg - Megalopsidiinae; Oxy - Oxyporinae; Pae - Paederinae; Pse - Pseudopsinae; Scy - Scydameninae; StGr - Staphylinine Group (inclusive Scydmaeninae); Sol - Solieriinae; Sta - Staphylininae; Ste - Steninae. Cell values: majority rule consensus tree value (if higher than $50 \%$ ) followed by bootstrap value. Cell color: black (branch highly supported: present on the strict consensus tree and boostrap value $50 \%$ and higher; scored 2 for both "support value" and "resolution value"); grey (branch moderately supported: present on the majority rule consensus tree and bootstrap value less than $50 \%$ OR absent on majority rule tree, but bootstrap value $50 \%$ and higher; scored 1 for both "support value" and "resolution value"); white (branch not supported: absent on the majority rule consensus tree and bootstrap less than $50 \%$; scored 0 for both "support value" and "resolution value").

Column SV/RSV (Support Value/Relative Support Value) is designed to demonstrate how strongly a given clade was supported throughout all 12 analyses; $\mathbf{S V}$ value as a sum of horizontal cell scores ( 0 for white cells; 1 for grey cells, 2 for black cells) with the maximum of 24 for clades fully supported in all 12 analyses; RSV value is a ratio of actual SV to the maximum value of 24 (16 for the clade of Ste+Eua $+\mathbf{S c y}+\mathbf{S o l}$, because lack of Solierus larval data preventing us from testing monophyly of the clade in the analyses 1-4); expressed in \%. Lowest row RV/RRV (Resolution Value/Relative Resolution Value) is designed to demonstrate how effective each of 12 analyses was to resolve phylogeny of the Staphylynine Group; RV value as a sum of vertical cell scores (0 for white cells; 1 for grey cells, 2 for black cells) with the maximum of 32 for an analysis giving fully resolved and strongly supported Staphylynine Group and all its internal branches of the level of subfamily and higher (not obtained in any of actual analyses); RRV value is a ratio of RV to the maximum value of 32 (30 for the analyses $1-4$, because lack of Solierus larval data is preventing us from testing monophyly of the $\mathbf{S t e}+\mathbf{E u a}+\mathbf{S c y}+\mathbf{S o l}$ clade in the analyses 1-4); expressed in \%.

\begin{tabular}{|c|c|c|c|c|c|c|c|c|c|c|c|c|c|}
\hline Analysis & & 1 & 2 & 3 & 4 & 5 & 6 & 7 & 8 & 9 & 10 & 11 & 12 \\
\hline Dataset & & & & & & dult & & & & & & & \\
\hline dered/unord & & & & & & nord. & & & & & & & \\
\hline hting & & no & yes & no & yes & no & yes & no & yes & no & yes & no & yes \\
\hline & & 255 & 699 & 259 & 71 & 590 & 725 & 594 & 728 & 874 & 1375 & & 1393 \\
\hline & & $41 / 78$ & $71 / 92$ & $40 / 78$ & $70 / 92$ & $27 / 62$ & $54 / 83$ & $26 / 63$ & $53 / 83$ & $30 / 66$ & $61 / 87$ & $30 / 67$ & $60 / 87$ \\
\hline st trees & & 77 & 3 & 54 & 3 & 8 & 2 & 1 & 3 & 1 & 1 & 3 & 1 \\
\hline Ste & $24 / 100 \%$ & $100 / 100$ & $100 / 99$ & $100 / 100$ & $100 / 100$ & $100 / 100$ & $100 / 100$ & $100 / 100$ & $100 / 100$ & $100 / 100$ & $100 / 100$ & $100 / 100$ & $100 / 10$ \\
\hline & & & $100 / 79$ & & & /83 & & & & & & & \\
\hline & & D/83 & $100 / 84$ & & $100 / 84$ & $100 / 90$ & $100 / 92$ & $100 / 93$ & & & & & \\
\hline & & $100 / 50$ & $100 /<50$ & $100 / 51$ & $100 /<50$ & $0 /<50$ & $\mid<50$ & & & & & & \\
\hline & & $100 /<50$ & $100 /<50$ & $100 /<50$ & $100 /<50$ & $100 /<50$ & $\mid<50$ & $<50$ & & $100 / 50$ & $100 / 52$ & & \\
\hline & & $\mathrm{n} / \mathrm{a}$ & $\mathrm{n} / \mathrm{a}$ & $\mathrm{n} / \mathrm{a}$ & $\mathrm{n} / \mathrm{a}$ & $87 /<50$ & $100 /<50$ & $<50$ & & $0 /<50$ & $100 /<50$ & $0 /<50$ & $100 /<50$ \\
\hline & & $100 / 97$ & $100 / 97$ & $100 / 97$ & $100 / 97$ & $0 /<50$ & $0 /<50$ & & & $100 / 84$ & & $100 / 89$ & $100 / 88$ \\
\hline & & & & & & $100 /<50$ & $0 /<50$ & & $100 /<50$ & & & & \\
\hline & & $100 / 89$ & $100 / 90$ & $100 / 91$ & 100/92 & $0 /<50$ & $100 /<50$ & $100 /<50$ & $0 /<50$ & 0/97 & & & $/ 97$ \\
\hline & & $0 /<50$ & $0 /<50$ & $0 /<50$ & $0 /<50$ & $75 / 53$ & $100 / 54$ & $0 / 50$ & $100 /<50$ & $100 / 61$ & & & $100 / 54$ \\
\hline & & $100 / 99$ & & & & $0 /<50$ & $0 /<50$ & $0 /<50$ & $0 /<50$ & $100 / 80$ & $100 / 81$ & $100 / 78$ & $100 / 78$ \\
\hline & & & & & & $100 / 99$ & $100 / 99$ & $100 / 99$ & $100 / 99$ & $100 / 100$ & $100 / 100$ & $100 / 100$ & $100 / 100$ \\
\hline & & $100 / 60$ & $100 / 57$ & $100 / 59$ & $100 / 58$ & $0 /<50$ & $0 /<50$ & $100 /<50$ & $0 /<50$ & $100 /<50$ & $100 /<50$ & $<5$ & $100 /<5$ \\
\hline & $18 / 75 \%$ & $100 / 78$ & $100 / 74$ & $100 / 78$ & $100 / 78$ & $100 /<50$ & $0 /<50$ & $100 /<50$ & $0 /<50$ & $100 / 79$ & $100 / 78$ & $100 / 80$ & $100 / 79$ \\
\hline & & & & & & & & & & $100 / 52$ & & $100 / 58$ & $100 / 59$ \\
\hline & & & & & $100 /<50$ & & & & & $100 /<50$ & $100 /<50$ & & $100 /<50$ \\
\hline V/RRV & & $3 / 76 \%$ & $24 / 80 \%$ & $23 / 76 \%$ & $24 / 80 \%$ & $13 / 40 \%$ & $15 / 47 \%$ & $17 / 53 \%$ & $17 / 53 \%$ & $28 / 88 \%$ & $29 / 90 \%$ & $28 / 88 \%$ & $29 / 90^{\circ}$ \\
\hline
\end{tabular}

exact wording of all characters was then reviewed by both coauthors and changes were made to reach a consensus.

Both larval and adult morphological data were scored, in most of the cases, for the same species. In cases when this was impossible because of material limitation, different congeneric species were used, creating a few "chimera" terminals. It is assumed, however, that in such cases these species are more closely related to one another than to any other terminal in the same matrix and, therefore, larval and adult datasets might be merged without creating a phylogenetic conflict of incompatible terminals.

We analysed three separate morphological datasets: larval (characters 1-89), adult (characters 90-211), and combined (characters 1-211) using for each of them four possible combinations of ordering and weighting parameters (Table 2). In total,
12 separate analyses of morphological data were implemented, as summarized in Table 2.

Three software packages were applied to the morphological data. Hennig86 (Farris, 1988) was used to search for the shortest (= most parsimonious) trees (single heuristic search; commands "mh*" and "bb*") and then to perform successive approximations (Farris, 1969; executed by a string of commands "xs w", "mh*" and "bb" repeated in cycles until the tree statistics stabilised). Branch support was assessed using Nona 2.0 (Goloboff, 1999) through bootstrapping 1000 randomly generated trees. Winclada (Nixon, 2002) was used as a shell program to construct the matrix and to communicate with both Hennig86 and Nona.

To make an unambiguous judgement on the strength of the clade support and to compare the capacity of each of the 12 morphological analyses to consistently resolve the Staphylinine 


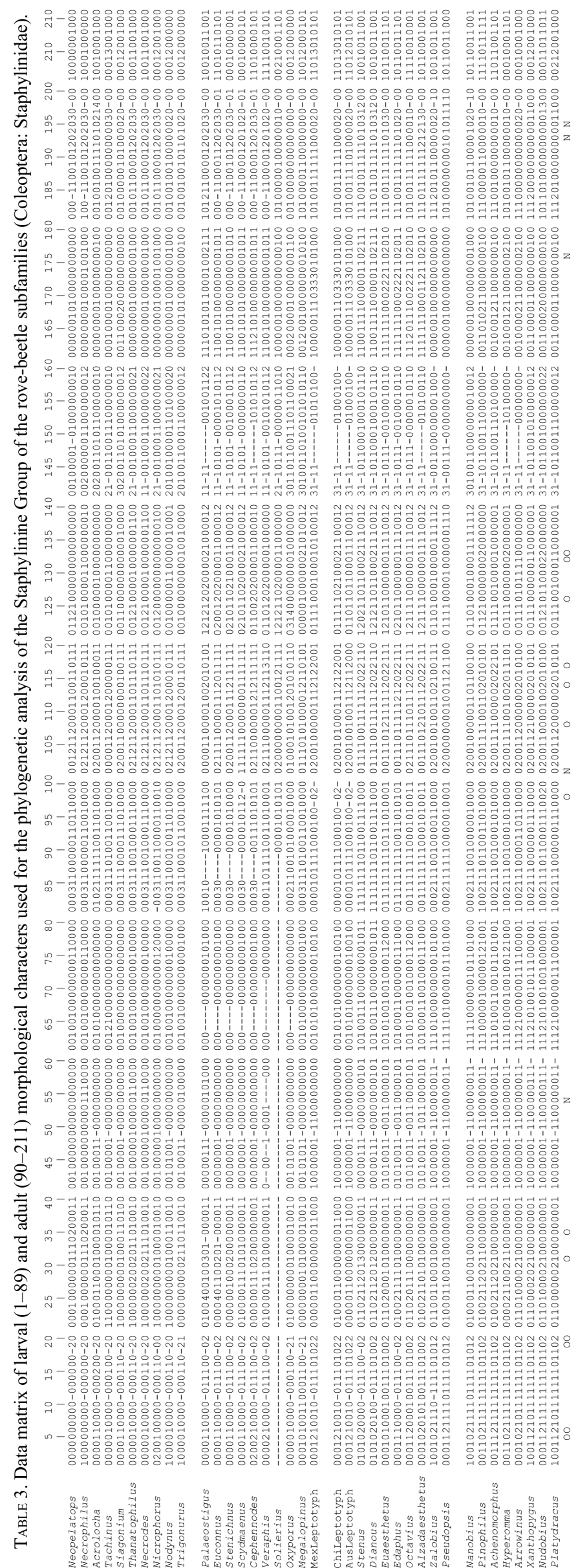

Group and its subordinate clades, we introduced the statistical measures "Relative Support Value" (for clades) and "Relative Resolution Value" (for analyses). Both values are expressed as a percentage and are explained in Table 2.

\section{$18 S$ rDNA datasets and analysis}

Two sets of four different analyses were implemented using ClustalX- and MAFFT-based alignments, respectively; thus in total eight DNA-based analyses were run. The first ClustalX-based 18S analysis searched for the shortest trees utilizing 612 parsimoniously informative characters (in Nona; commands "hold = 1000"; "mult* $\mathrm{N}=10$ "; "hold/ = 2"; "mult*max*" activated). The second ClustalX-based analysis utilized the same 612 character matrix, in which three groups of characters with the highest number of insertions/deletions were visually selected and removed (characters 62-96, 208-266 and 422-479; characters numbered from 1); the resulting matrix contained 454 characters and was analysed with Hennig86 using commands mh* and $\mathrm{bb}^{*}$. The third ClustalX-based analysis utilized the complete aligned matrix (93 taxa, 2095 characters) and the neighbourjoining algorithm implemented in PAUP for Windows version 4.0b1 (Swofford, 2000) by using command "nj". The fourth ClustalX-based analysis utilized the same complete aligned matrix using Bayesian topology-building algorithm implemented in MrBayes version 3.1.1 (Ronquist \& Huelsenbeck, 2003) with a general time reversible model with proportion of invariable sites and unequal rates $(\mathrm{GTR}+\mathrm{I}+\mathrm{G}$; executed by commands "lset nst $=6$ rates $=$ invgamma") and the following settings: "mcmc ngen = 3000000"; "sumt burnin $=2000 "$ "; three heated and one cold Markov chains. Setting the number of generations in both Bayesian analyses at 3,000,000 and the number of discarded topologies at 20,000 (representing first 2,000,000 generations; one topology is saved every 100 generations) we selected the last $1,000,000$ generations (or last 10,000 topologies) to be used for the resulting majority-consensus tree. The obtained "con" file with the resulting topologies was visualised in Dendroscope (Huson et al., 2007), exported as an image and edited in CorelDraw.

A further four similarly designed analyses used MAFFTbased matrix. The first MAFFT-based analysis was implemented identically to the first ClustalX-based one (see above), although the number of parsimoniously informative characters was 591. The second MAFFT-based analysis utilized the 591 character matrix, in which three groups of characters with the highest number of insertions/deletions were visually selected and removed (characters 62-96, 211-247 and 411-449; characters numbered from 1); the resulting matrix contained 478 characters and was analysed similarly as ClustalX-based analysis 2 (described above). Third and fourth MAFFT-based analyses used neighbour-joining and Bayesian algorithms, respectively, and were executed as corresponding ClustalX-based analyses (described above).

\section{RESULTS OF THE CLADISTIC ANALYSIS}

\section{Parsimony analysis of morphological data}

The results of 12 parsimony analyses of morphological data are summarized in Table 2. Fig. 14 is the fully resolved majority consensus subfamily-level tree, representing the most consistent topology obtained from the parsimony analyses of the Staphylinine Group based on morphological data; the position of Solierius remains uncertain on this tree. To facilitate further discussion, all 12 analyses are grouped into three sets 
based on the source and comprehensiveness of data used: larval (analyses 1-4), adult (analyses 5-8) and combined (analyses 9-12); the former two are also called "partial". For convenience, the Staphylinine Group of rove-beetle subfamilies as defined in Material and methods (including Scydmaeninae as a subfamily) will be referred to as sensu lato; the same group, excluding Oxyporinae and Megalopsidiinae, will be sensu stricto.

Within the scope of our morphology-based analysis, all non-monogeneric subfamilies were recovered as monophyletic in most of analyses. Statistical support for monophyly of individual subfamilies was predominantly consistent and sometimes very high, as in Steninae (two genera included), Euaesthetinae (three genera included) and Leptotyphlinae (three genera included). These three clades were invariably found on strict consensus trees in all 12 analyses. Moreover, these clades were strong enough to withstand bootstrapping and possessed relatively very high bootstrap values (99-100\% for Steninae and Leptotyphlinae; 79-97\% for Euaesthetinae); in combined analyses these values were the highest. The Relative Support Value for each of these clades is $100 \%$ (Table 2).

Three other subfamilies, Scydmaeninae, Staphylininae and Paederinae, represented by six, four and three genera, respectively, were recovered as monophyletic. These subfamilies were more strongly supported in larval analyses than in adult ones, where each of them was recovered as non-monophyletic at least once on the majority-rule consensus tree (Table 2). Combined analyses, however, consistently maintained each of these subfamilies as a clade on either strict consensus or bootstrap trees with the relatively high bootstrap values varying between 66 and $89 \%$. Relative Support Values for these clades are 75\%, 75\% and $79 \%$, respectively (Table 2 ).

Pseudopsinae, with three genera included in the analysis, is the only remaining non-monogeneric in-group subfamily, and was the least supported (Relative Support Value 54\%). All larval analyses invariably failed to maintain it as a clade; instead, it was shown as paraphyletic with respect to Staphylininae + Paederinae. The adult analyses, on the other hand, moderately to strongly supported monophyly of Pseudopsinae. The combined analyses invariably recognized Pseudopsinae as a clade on all four strict consensus trees and, furthermore, this clade was consistently able to withstand bootstrapping with moderate bootstrap value varying between 52 and $61 \%$.

The most consistently supported and fully resolved tree of the Staphylinine Group (Fig. 14) includes two clades formed by two individual subfamilies. One clade, constituted by Steninae and Euaesthetinae, is the most strongly supported group above the subfamily level recovered in our analysis. This clade was consistently detected on strict consensus of all shortest trees found in all 12 analyses and, moreover, its bootstrap support was always high to very high, varying between 83 and 99\% (combined analyses having the highest bootstrap values). The Relative Support Value for this clade is $100 \%$.
Another two-subfamily clade is formed by Staphylininae and Paederinae, with a Relative Support Value of $75 \%$. This clade was consistently recovered on strict consensus and bootstrapped trees in the larval analyses, but became paraphyletic with respect to the rest of Staphylinine Group sensu stricto in half of the adult analyses. Combined analyses, however, consistently supported Staphylininae and Paederinae as a clade with bootstrap values even higher than those in separate larval analyses (Table 2).

Two other in-group clades on the most consistently supported and fully resolved tree of Staphylinine Group (Fig. 14) include three individual subfamilies. One clade was the consistently resolved monophylum of Scydmaeninae + (Steninae + Euaesthetinae), which was always recovered on the strict consensus of all shortest trees in all eight partial analyses with different combinations of assumptions (character ordering and weighting) and based on either larval or adult morphological data. Statistical support of Scydmaeninae being a sister to Steninae + Euaesthetinae in either larval or adult analyses was moderately high, and this clade was invariably lost after bootstrapping the trees. Combined analyses also consistently placed Scydmaeninae as a sister to Steninae and Euaesthetinae on all four strict consensus trees and, unlike the partial datasets, this clade was strong enough to always withstand bootstrapping (Table 2). This clade's Relative Support Value is $67 \%$.

The second three-subfamily clade is that of Pseudopsinae + Paederinae + Staphylininae, which was strongly supported in larval and combined analyses, but the adult analyses invariably showed it as paraphyletic either to the rest of Staphylinine Group sensu stricto or, in one case, to Leptotyphlinae. These conflicting results are the main discrepancy between the larval and adult datasets found in the present analysis, however, the combined analyses resulted in detection of a strong and clear phylogenetic signal corroborating that from the larval dataset (see Discussion below). The Relative Support Value for this clade is $67 \%$, which is equal to that of Scydmaeninae + (Steninae + Euaesthetinae).

The only four-subfamily clade recovered on the most consistently supported topology consists of Leptotyphlinae + Pseudopsinae + Paederinae + Staphylininae. This clade was invariably recovered and strongly supported in all larval analyses, but was lost all but once in the adult analyses. The combined analyses always recovered this clade on all strict consensus trees, but invariably lost it after bootstrapping (Table 2). The Relative Support Value for this clade is $54 \%$, which is equal to that of supposedly monophyletic Pseudopsinae.

Moving further down the most consistently supported tree (Fig. 14), the Staphylinine Group sensu stricto (excluding Oxyporinae and Megalopsidiinae) was consistently and strongly supported as monophyletic in all larval and combined analyses. Only half of the adult analyses recovered it on their strict consensus trees but it was lost after bootstrapping (Table 2). The Relative Support Value for this clade is $75 \%$. The same clade, but with 


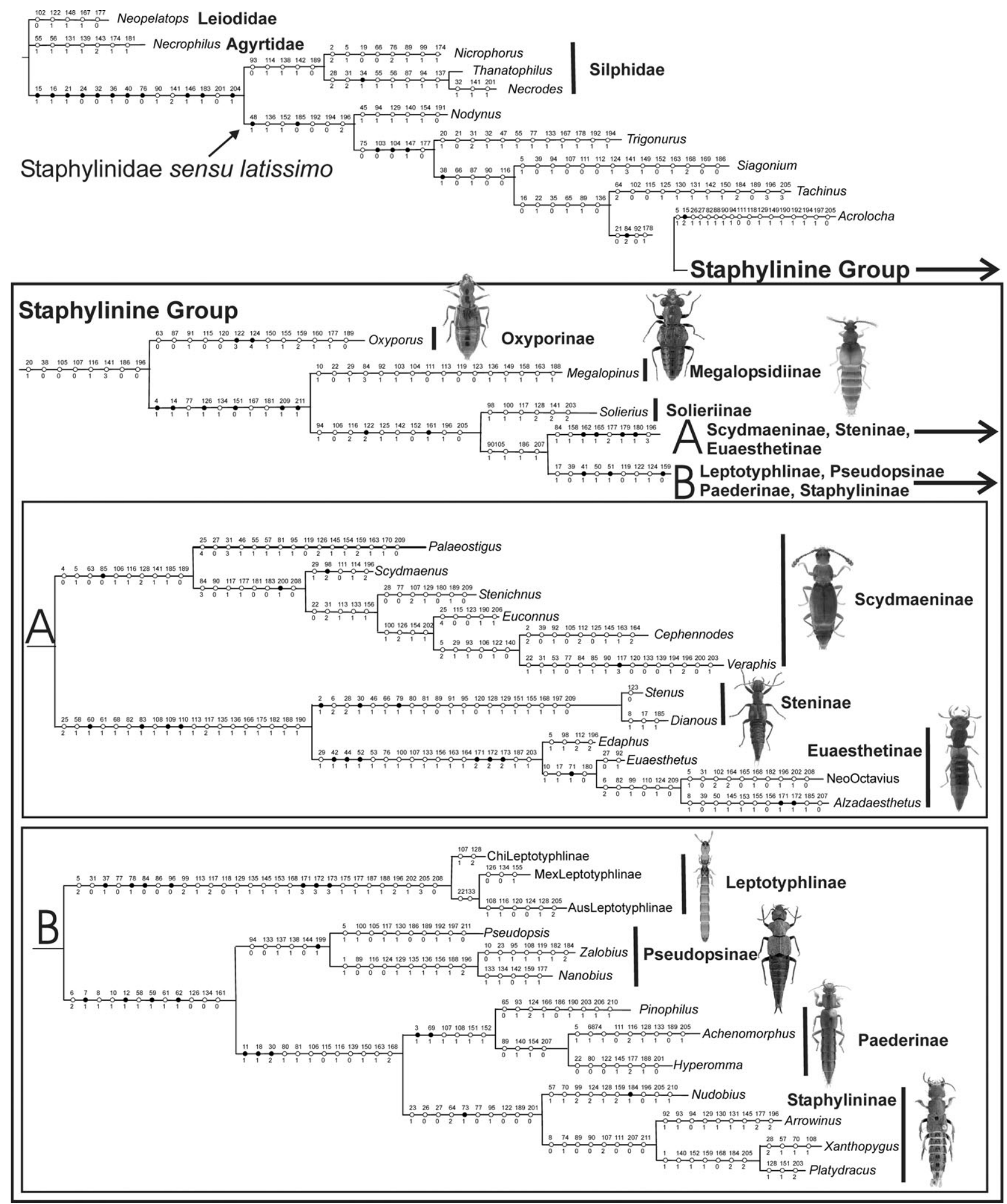

Fig. 11. Single most parsimonious tree from combined analyses of larval and adult morphological data with all characters unordered and not weighted (analysis 9) and with unambiguously optimized evolutionary events plotted along internodes. Character numbers are above circles; newly acquired character states are below circles. Black circles indicate unique evolutionary events; white circles indicate parallelisms or reversals. Lack of larval data for Solierius led to an artifact: larval characters potentially informative just above and just below this taxon's branching off its sister-group became ambiguously optimized on the tree and, therefore, not phylogenetically informative.

addition of Megalopsidiinae, was recovered on strict consensus trees in half of either larval or adult analyses and not maintained in the bootstrap analysis; in combined analyses this clade was invariably recovered on either strict consensus or on bootstrap trees with a Relative Support Value of $50 \%$. 


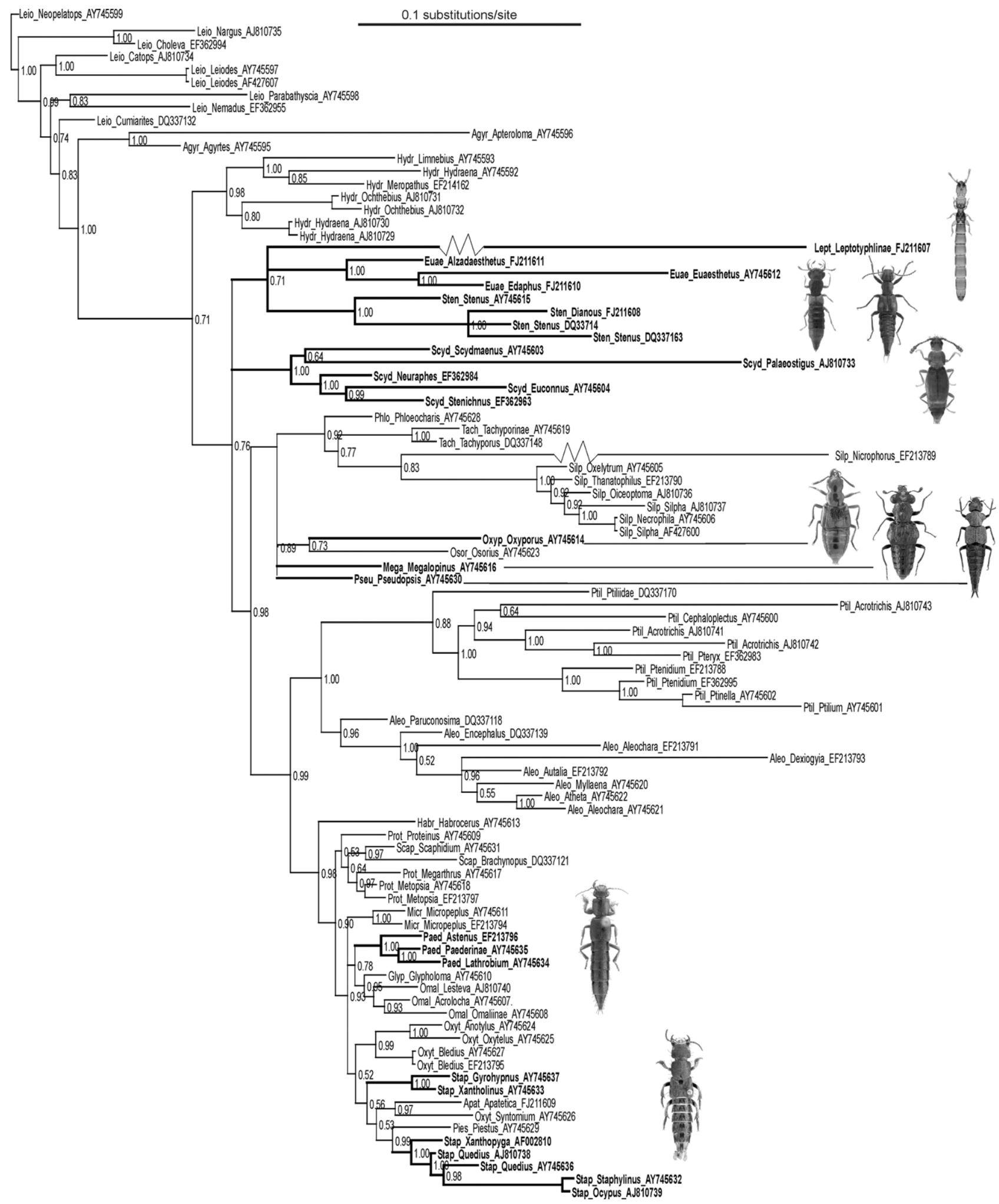

Fig. 12. Fifty percent majority-rule Bayesian consensus topology for fourth ClustalX-based analyses (18S analysis \#4). Posterior probabilities are indicated at respective branches. Members of Staphylinine Group are in bold. First four letters in terminal name indicate family (or subfamily for Staphylinidae), followed by the generic name and by GenBank accession number. Branch lengths are proportional to evolutionary distance; those for Leptotyphlinae and Nicrophorinae are shortened to fit on page.

The Staphylinine Group of rove-beetle subfamilies (sensu lato including Oxyporinae and Megalopsidiinae branching off basally to the rest of the clade) was consistently recovered on all shortest topologies from analyses
9-12 (combined larval and adult data). The bootstrap value of this clade, however, was always below $50 \%$. Analyses of the separate larval or adult datasets were less consistent, recovering this clade twice and once, respec- 

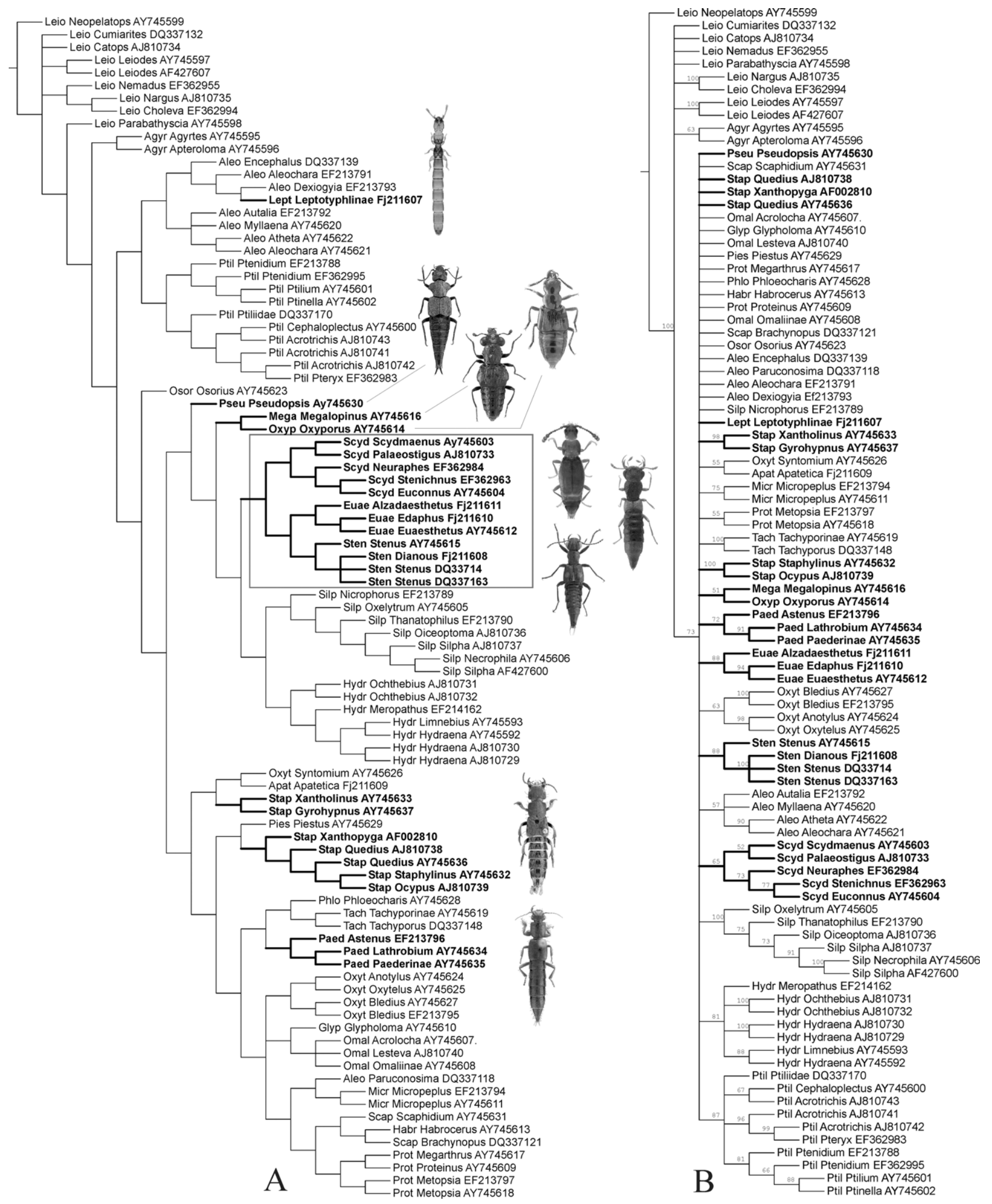

Fig. 13. Strict consensus (A) and 50\% majority rule consensus bootstrap (B) trees for MAFFT-based parsimony analysis (18S analysis \#5). Members of Staphylinine Group are in bold; clade of Scydmaeninae + (Steninae + Euaesthetinae) is boxed. Bootstrap values are marked above internodes. First four letters in terminal name indicate family (or subfamily for Staphylinidae), followed by the generic name and by GenBank accession number.

tively. This clade is the most weakly supported of all 16 in-group clades (Table 2) having the lowest Relative Support Value of $29 \%$. Monophyly of the Staphylinine
Group, however, is still the most parsimonious hypothesis resulting from our morphology-based analysis, which is only disrupted occasionally on the shortest trees by one of 


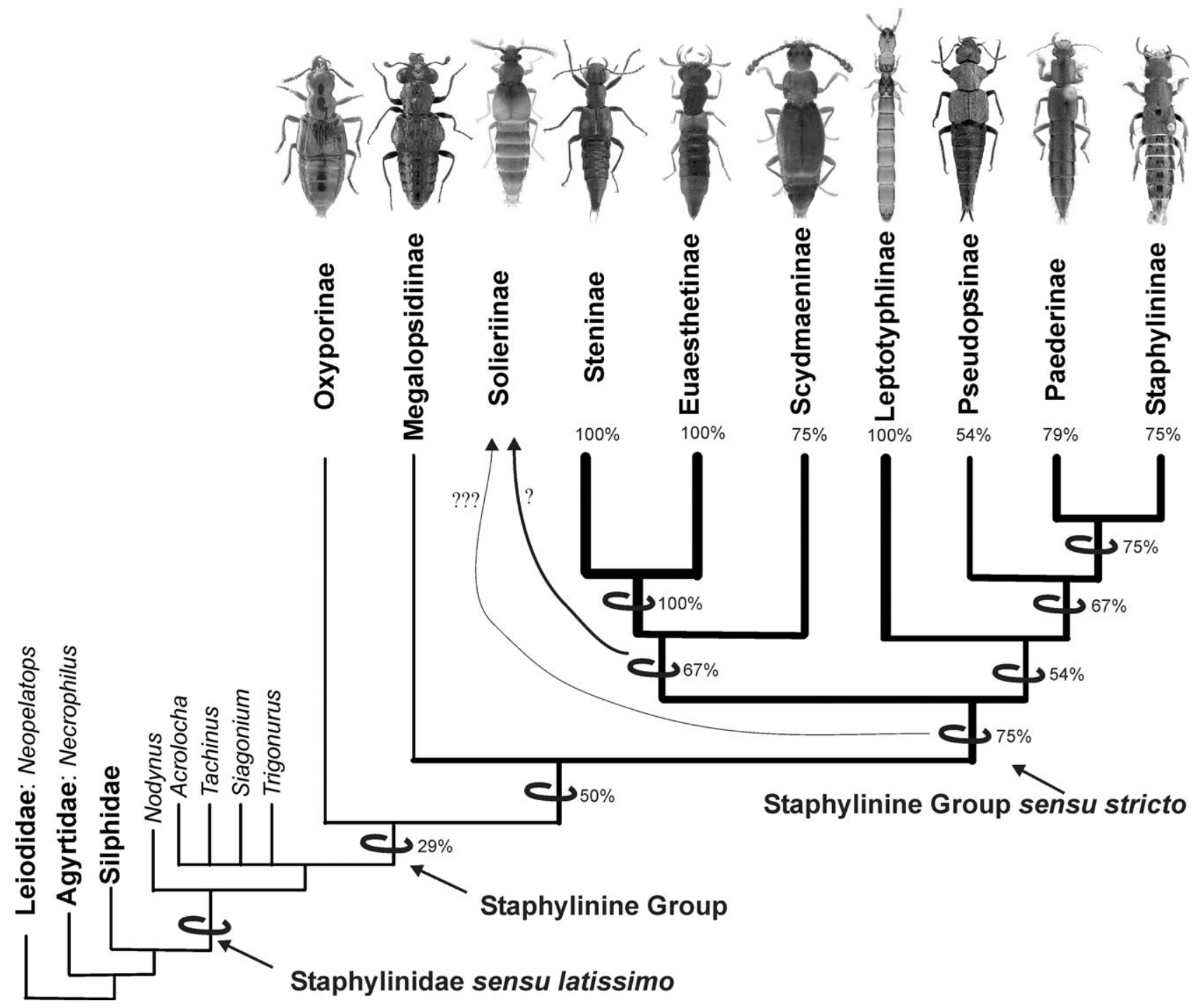

Fig. 14. Single fully resolved and most consistently supported topology of the Staphylinine Group of rove-beetle subfamilies. Width of internodes is proportional to the Relative Support Value for each clade. Phylogenetic position of Solierius is uncertain.

the outgroup genera being inconsistently absorbed into it and branching off at the first or second most basal node.

\section{Parsimony, neighbour-joining, and Bayesian analysis of $18 \mathrm{SDNA}$ data}

Besides morphological, eight DNA-based analyses were implemented, none of which resulted in either Staphylinidae (sensu latissimo) or Staphylinine Group (either sensu lato or sensu stricto) being strictly monophyletic. The first ClustalX-based analysis (parsimony; 93 taxa and 612 characters) produced eight shortest trees 4,331 steps long, with a consistency index of 27 and a retention index of 58. Strict consensus of the shortest trees (not illustrated) showed the monophyletic Euaesthetinae as a sister to the dichotomy of monophyletic Ptiliidae + a clade containing the paraphyletic remainder of the Staphylinidae sensu latissimo and the monophyletic Silphidae and Hydraenidae. Within that latter branch, non-monophyletic Scydmaeninae formed a clade together with Leptotyphlinae and Osoriinae. Bootstrapping of this tree resulted in a large polytomy of all taxa minus Leio- didae and Agyrtidae, and with the following groups maintained as clades (bootstrap values in brackets): Euaesthetinae (95\%), Steninae (82\%), Staphylininae (55\%), Scydmaeninae (54\%), Silphidae without Nicrophorus (100\%), Hydraenidae (63\%) and Ptiliidae (92\%).

The second ClustalX-based parsimony analysis of the $18 \mathrm{~S}$ sequence data (93 taxa and 454 characters) resulted in eight shortest trees 3,091 steps long (consistency index $=27$; retention index $=42$ ). Strict consensus of the shortest trees (not illustrated) shows monophyletic Euaesthetinae and single Oxyporinae nested within Steninae with this combined clade being a sister to monophyletic Scydmaeninae. Bootstrapping of this tree (not illustrated) created a large polytomy overall similar to the one obtained in the previous analysis, but without monophyletic Staphylininae and with a monophyletic clade of Euaesthetinae + Steninae (bootstrap value 53\%).

The single fully-resolved topology resulting from the third ClustalX-based neighbour-joining analysis (not illustrated) shows a grade of Leiodidae with the following lineages branching subsequently off: (01.) Agyrtidae; 
then (02.) Silphidae paraphyletic with respect to Palaeostigus (Scydmaeninae) and Leptotyphlinae; then (03.) Euaesthetinae and Steninae; then (04.) Hydraenidae + Ptiliidae; then (04.) Aleocharinae paraphyletic with respect to Oxyporus and without Paraconosoma; leaving the rest of Staphylinidae sensu latissimo, including a clade of Scydmaeninae minus Palaeostigus.

Consensus topology obtained as a result of the Bayesian analysis [fourth ClustalX-based analyses; Fig. 12; standard deviations for the last (the third) million of generations decreased from 0.032909 to 0.012169 ] shows a branch of all analysed taxa minus Leiodidae with the following lineages branching subsequently off (posterior probability multiplied by 100 for the mentioned clade is indicated in square brackets followed by that of its respective sister-group): (01.) Agyrtidae [100/71]; then (02.) Hydraenidae [98/76]; then (03.) unresolved trichotomy of (A.) Leptotyphlinae + Euaesthetinae + Steninae [71]; (B.) Scydmaeninae [100]; (C.) the rest of analysed taxa [98]; then within branch $C$ (04.) ((Silphidae + Tachyporinae $)+$ Phloeocharinae $)+($ Osoriinae + Oxyporinae) + Megalopsidiinae [89/99]; then (05.) Ptiliidae + Aleocharinae [100/98]; then the rest of the analysed taxa.

The first MAFFT-based analysis (parsimony; 93 taxa and 591 characters) produced 73 shortest trees 3,547 steps long, with consistency index of 29 and retention index of 49. Strict consensus of the shortest trees (Fig. 13A) shows the monophyletic Scydmaeninae as a sister to a clade of Steninae + Euaesthetinae (both monophyletic). Bootstrapping of this tree resulted in a large polytomy (Fig. 13B) with the following groups maintained as clades (bootstrap values in brackets): Euaesthetinae (88\%), Steninae (88\%), Oxytelinae without Syntomium (63\%), Paederinae (72\%), Scydmaeninae (54\%), Silphidae without Nicrophorus (100\%), Hydraenidae (81\%) and Ptiliidae (87\%).

The second MAFFT-based analysis of the $18 \mathrm{~S}$ sequence data (parsimony, 93 taxa and 478 characters) resulted in an overflow of at least 1,031 shortest trees 2,623 steps long, consistency index 30, retention index 49. Strict consensus of the shortest trees and the bootstrap tree (both not illustrated) are markedly similar is shape and have a large polytomy of all taxa excluding Leiodidae and Agyrtidae with the following groups maintained as clades (bootstrap values in brackets): Staphylininae (53\%) paraphyletic with respect to a clade (69\%) of Euaesthetinae (88\%) and Steninae (93\%), Oxytelinae without Syntomium (70\%), Paederinae (90\%), Scydmaeninae (85\%), Silphidae without Nicrophorus (100\%), Aleocharinae $(67 \%)$ paraphyletic with respect to Leptotyphlinae, Hydraenidae (68\%) and Ptiliidae (88\%).

The single fully-resolved topology resulting from the third MAFFT-based analysis (neighbour-joining; not illustrated) shows a grade of Leiodidae with the following lineages branching subsequently off: (01.) Agyrtidae; then (02.) Ptiliidae + Palaeostigus (Scydmaeninae), Nicrophorus (Silphidae) and single member of Leptotyphlinae; then (03.) Euaesthetinae and Steninae; then (04.) Hydraenidae; then (05.) Aleocharinae without Para- conosoma; leaving the rest of Staphylinidae sensu latissimo, including a clade of Scydmaeninae minus Palaeostigus.

Consensus topology obtained as a result of the Bayesian analysis [fourth MAFFT-based analysis; not illustrated; standard deviations for the last (the third) million of generations decreased from 0.103797 to 0.059271 ] shows a branch of all taxa except Leiodidae and Agyrtidae (posterior probability multiplied by 100 for the mentioned clade is indicated in square brackets) further splitting into a trichotomy of Hydraenidae [81], Ptiliidae [100] and Silphidae + Staphylinidae (sensu latissimo) [100]. The latter branch includes the basal polytomy of 18 branches, among them a branch of Leptotyphlinae + Steninae + Euaesthetinae [74], as well as a branch consisting of all five included genera of Scydmaeninae [100].

\section{DISCUSSION}

\section{On predominantly consistent morphology-based topologies versus inconsistent DNA-based topologies}

Comparison of topologies obtained in 12 morphologybased parsimony analyses demonstrates that most of the clades are consistently recovered with a few notable exceptions (see below). Conversely, eight 18S rDNAbased analyses utilizing the principle of parsimony (four analyses), neighbour-joining clustering and Bayesian approach (two analyses each, respectively) demonstrate remarkable inconsistency when compared (a) among themselves; (b) with the results of morphology-based analyses, such as monophyly of Steninae + Euaesthetinae; (c) with some strongly-supported pre-existing hypotheses on the relationships within Staphylinoidea, such as monophyly of Ptiliidae + Hydraenidae, or monophyly of individual subfamilies such as Staphylininae. Previous authors have already noted this limitation of the small ribosomal subunit (18S rDNA) in providing strong and clear phylogenetic signals at the subfamily/family level of relationships in Coleoptera (Maddison et al., 1999), attributing it to the inconsistent rate of divergence among taxa (Caterino et al., 2005). Another seemingly significant factor is the apparent inadequacy of any alignment not based on the information of the secondary structure of length-variable non-coding genes, such as $18 \mathrm{~S}$ rDNA, to correctly insert the relatively high number of gaps, and thus to maintain character homology in the fully aligned matrix (Kjer, 2004). We conclude that the results of our eight DNA-based analyses are too inconsistent to be included in our phylogeny and we base our conclusions almost entirely on our morphological results. In one case (Fig. 12), however, the sequence data strongly supported the grouping of Scydmaeninae with Steninae + Euaesthetinae, which is fully consistent with the morphology-based results.

\section{On limitations and overall degree of monophyly confidence for recovered clades}

In discussing our morphology-based analysis, it is important to stress that the confidence in the presented results must be judged within the limitations imposed on 
our ability to infer subfamily-level phylogeny of such a megadiverse group as the rove-beetles, which is currently the most speciose clade of animals conventionally accepted as a family. The Staphylinine Group itself, as presently accepted, includes 21,679 species and 1,702 genera. It was necessary, therefore, to restrict ourselves to only a few terminal taxa to represent each of these clades in order to address our target question with the realistic prospect of achieving meaningful results in a reasonable time frame.

The single most consistently and fully resolved topology presented on Fig. 14 has Relative Support Values from Table 2 plotted against each clade. The proposed statistical measure is the single best value we can offer to judge the relative support for each clade. This support has its maximum of $100 \%$ in Leptotyphlinae, Steninae, Euaesthetinae and a clade of the two latter subfamilies. This indicates that any of these four clades was present on every strict consensus tree in 12 morphologybased analyses, and this clade withstood bootstrapping. Medium-strong support with Relative Support Values between 67 and 79\% was found in seven clades: Scydmaeninae; Steninae + Euaesthetinae + Scydmaeninae; Staphylininae; Paederinae; Staphylininae + Paederinae; Pseudopsinae + Staphylininae + Paederinae; and for the whole of Staphylinine Group (excluding Oxyporinae and Megalopsidiinae). Three other clades showing medium Relative Support Values are: Pseudopsinae (54\%); Leptotyphlinae + Pseudopsinae + Staphylininae + Paederinae (54\%); and the entire Staphylinine Group except Oxyporinae $(50 \%)$. The lowest support value of $29 \%$ was found for the whole of the Staphylinine Group. The most parsimonious (although still considered as too ambiguous because of the lack of larval data) position of Solieriinae is that of a sister to Scydmaeninae + Steninae + Euaesthetinae. With the single exception of the entire Staphylinine Group sensu lato, all discussed clades have Relative Support Values of 50\% and more. Even the Staphylinine Group sensu lato, the least supported clade with only $29 \%$, is still the most consistently recovered hypothesis compared to any alternatives (see Results above). These considerations suggest that the overall support obtained in our analysis for the fully resolved topology of the Staphylinine Group of rove-beetle subfamilies is significant enough not to reject it.

\section{On relative contribution of larval versus adult morphological characters and on conflicting results within morphology-based analyses}

The Relative Resolution Value (expressed as a percentage; the last row of Table 2) offers a possibility to compare the strength of each among 12 individual morphological analyses in resolving topologies at and above subfamily level within the Staphylinine Group in a way consistent with the fully resolved most parsimonious topology (Fig. 14). The first four analyses based on larval morphology were consistently more powerful (RRV 76-80\%) in detecting clades within Staphylinine Group, when compared to the four adult-based analyses (RRV 40-53\%). The four combined datasets analyses, as it would be expected, were able to resolve all (analyses 10 and 12) but one clade (analyses 9 and 11) in a manner consistent with the fully resolved most parsimonious topology of the Staphylinine Group (as shown on Fig. 14). We therefore conclude that the analyses based on larval morphological data were more informative in detecting phylogenetic signal within the Staphylinine Group of rove-beetle subfamilies than those based on adult morphology, and merging both datasets resulted in significantly better resolution power when compared to individual partial analyses.

The main inconsistency in our morphology-based results is the failure of the adult analyses to detect the monophylum Pseudopsinae + Paederinae + Staphylininae (one of the most strongly supported pre-existing hypotheses: Grebennikov, 2005; Solodovnikov \& Newton, 2005) and, consequently, the more inclusive clade including Leptotyphlinae as a sister to these three subfamilies (Fig. 14). Both clades are strongly supported by the larval analyses, but in the adult analyses are almost always shown as variably paraphyletic to some other in-group taxa (see Results). None among these unexpected adultbased topologies has been previously considered as a viable phylogenetic hypothesis and, moreover, the merging of adult and larval characters firmly settles this inconsistency in favour of the larval dataset. We conclude, therefore, that this inconsistency reflects an artefact embedded in the set of adult characters which is not strong enough to significantly overshadow a consistent phylogenetic signal remaining within the adult matrix and further strengthened by a corroborating signal from the larval dataset. A similar phenomenon was detected with Pseudopsinae, a subfamily which was not recovered in the larval analyses, but became moderately supported in the adult analyses, and emerged as a strongly supported clade in the combined dataset. Such results reinforce our earlier observation that merging both partial datasets into a single combined source of data allowed us to recover a single fully resolved and consistently supported topology (Fig. 14), in spite of the occasional lack of clear phylogenetic signals detected in both partial datasets.

\section{On the position of Scydmaeninae, the ant-like stone beetles, and a revised status and classification of the group}

The most significant feature of our morphology-based results is that the consistently resolved clade Scydmaeninae + (Steninae + Euaesthetinae) is invariably included within the monophyletic Staphylinine Group (either sensu stricto or sensu lato). This result is neither consistently supported nor excluded (Fig. 12) in the molecular analysis, while the overall results of our $18 \mathrm{~S}$ rDNA-based analysis are judged as "inconclusive" to address phylogeny of our target group (see above). Our results strongly and consistently support the initial hypothesis that the Staphylinine Group is paraphyletic with respect to "Scydmaenidae", a result consistent with several earlier studies (see Introduction). Consequently, in order to resolve this paraphyly, we conclude that it is now time that "Scydmaenidae" be formally included in Staphy- 
linidae sensu latissimo and constitute yet another, the 32nd, Recent subfamily of this megadiverse family of rove-beetles, Scydmaeninae status novus. This action necessitates modifying the internal classification of the former "Scydmaenidae", which included three subfamilies and numerous tribes. This is most easily accomplished by downgrading the three previously recognised subfamilies to the supertribes Scydmaenitae, Mastigitae and Hapsomelitae status novus, in a manner consistent with similar taxonomic action towards the former "subfamilies" of Pselaphinae (Newton \& Thayer, 1995), and leaving the classification at the tribal and lower levels as is. The classification above the generic level of the former "Scydmaenidae" resulting from these actions can then be represented as follows, modified from the recent world classification of Newton \& Franz (1998) and incorporating other recent changes and additions (most implemented in Newton \& Thayer, 2005):

STAPHYLINIDAE Latreille, 1802, sensu novo et latissimo: 32 Recent and one extinct subfamilies (Herman, 2001; Thayer, 2005), including:

SCYDMAENINAE Leach, 1815, stat. $\mathrm{n}$.
SCYDMAENITAE Leach, 1815, stat. $\mathrm{n}$.
EUTHEIINI Casey, 1897
CEPHENNIINI Reitter, 1882
CYRTOSCYDMINI Schaufuss, 1889
PLAUMANNIOLINI Costa Lima, 1962
CHEVROLATIINI Reitter, 1882
LEPTOSCYDMINI Casey, 1897
SCYDMAENINI Leach, 1815
MASTIGITAE Fleming, 1821, stat. n.
CLIDICINI Casey, 1897
LEPTOMASTACINI Casey, 1897
MASTIGINI Fleming, 1821
†HAPSOMELITAE Poinar \& Brown, 2004, stat. n.

Note that a complete catalog of genus- and familygroup names of Scydmaeninae stat. n., with full references, was provided in Newton \& Franz (1998) and Newton \& Thayer (2005). O'Keefe (2005) also provided a generic summary as well as a concise description of larvae and adults of the group, and summarized the results of his still-unpublished phylogenetic analysis within the group that suggested that Scydmaenitae are paraphyletic with respect to Mastigitae, and that Eutheiini and Cephenniini branch off first.

\section{On the position of Solierius}

The single significant uncertainty depicted on the most consistently supported topology is the position of the genus Solierius, the sole member of the subfamily Solieriinae (Fig. 14). Larvae of Solierius are still unknown and this is the only terminal in our analysis lacking larval morphological data and, consequently, a phylogenetic placement on the trees obtained in the larval analyses 1-4. Analysis of adult morphological characters (5-8) and two analyses of combined datasets (10 and 12) consistently placed Solierius as a sister to the clade of Scydmaeninae + (Steninae + Euaesthetinae) on the strict consensus trees, but this grouping was invariably lost after bootstrapping. Two other combined analyses ( 9 and 11) moved Solierius one internode towards the base, making it a sister to (Scydmaeninae + Steninae + Euaesthetinae $)+($ Leptotyphlinae + Paederinae + Staphylininae + Paederinae). The former hypothesis on Solierius is supported, consequently, three times more than the latter. At present we conclude that Solierius most likely belongs to the Staphylinine Group sensu stricto (i.e., excluding Oxyporinae and Megalopsidiinae), however, its more resolved sister-group relationships will be better understood once its larva is known.

\section{On the position of Silphidae}

All recent phylogenetic studies mentioned in the Introduction except Hunt et al. (2007) have Silphidae coming out at the base of, or more often just outside of, Staphylinidae sensu lato, and our results placing this family as a sister group to Staphylinidae are consistent with this placement. No studies, including Hunt et al. (2007), have linked Silphidae specifically to any members of the Staphylinine Group as defined here. Thus the hypothesis of Lawrence \& Newton (1982) that Silphidae might be members of the Staphylinine Group can be considered rejected. Silphidae may instead be a sister group to Staphylinidae, or an isolated basal lineage within it, and its exact relationship to Staphylinidae sensu latissimo is in our opinion the most difficult remaining issue concerning the monophyly of Staphylinidae.

\section{Age of the Staphylinine Group based on the fossil record}

According to Grimaldi \& Engel (2005), the earliest known Staphylinidae sensu lato (considered by them as "the oldest definitive polyphagan beetle") is a stillunnamed genus and species with relatively short elytra from the Late Triassic of Virginia, dated approximately 230-220 mya. After a gap, the mid- to late Jurassic period (ca. 180-150 mya) has yielded a diverse assemblage of more than two dozen named extinct genera of Staphylinidae, all with short elytra and all but two of them placed in or resembling members of the modern subfamilies Omaliinae, Tachyporinae, Oxytelinae, Trigonurinae, Olisthaerinae and Piestinae (Herman, 2001; Newton \& Thayer, 1995), and evidently not attributable to the Staphylinine Group. The exceptions are two extinct genera of probable Staphylininae from upper Jurassic compression fossils in China (Zhang, 1988). Further named and unnamed genera attributable to Staphylininae are known from the Cretaceous period (e.g., Grimaldi \& Engel, 2005, Fig. 10.8; Herman, 2001), and an extinct genus of Euaesthetinae is known from Cretaceous amber (Lefebvre et al., 2005). Scydmaeninae appear at this time also, represented by two extinct genera, Palaeoleptochromus O'Keefe (O'Keefe et al., 1997) and Hapsomela (Poinar \& Brown, 2004), from Cretaceous ambers from Canada and Burma, respectively. The latter genus, dated at about 100-110 mya, was originally placed in its own extinct subfamily Hapsomelinae, based on the apparent presence of a "patella" (otherwise unknown in modern Insecta) between the femur and tibia of the prolegs. 
Although their proposed homology of this structure may be debatable (possibly it is a rare, bilaterally symmetrical teratology), Hapsomela is clearly a scydmaenine, and establishes a minimal age for Scydmaeninae that is consistent with the placement of this subfamily in the Staphylinine Group. Numerous additional fossils of Scydmaeninae, Staphylininae, Paederinae and some other subfamilies of the Staphylinine Group are known from the Tertiary period, especially from Baltic and other ambers of about Oligocene age, and include many species attributed to modern genera (e.g., Herman, 2001; Spahr, 1982). These data together suggest an origin of the Staphylinine Group by the Upper Jurassic and its diversification into recognizable modern subfamilies, including Scydmaeninae, by the Cretaceous.

\section{Leptotyphlinae, the Cretaceous clade of blind and wingless endogean beetles}

Our results strongly support the hypothesis that the minute soil-dwelling Leptotyphlinae with 525 named species from all continents except Asia (Grebennikov \& Newton, 2008) originated in the Cretaceous to form a sister-group to the major worldwide radiation of Pseudopsinae + Paederinae + Staphylinidae consisting of 54, 6,101 and 6,876 species, respectively (Thayer, 2005). Though no fossil data are available to additionally test this hypothesis, it is still most parsimonious to assume that the obligatory endogean way of life with such associated morphological traits as complete blindness and lack of hind wings were attributes of the Leptotyphlinae stem species. Such an assumption is rather remarkable, as it identifies Leptotyphlinae as one of the oldest, most widely distributed and simultaneously most speciose clades of blind and wingless soil-dwelling pterygote insects.

It is plausible to assume that the morphological ultraspecialization accompanied by losing eyes and severely reducing dispersal capacity, as found in Leptotyphlinae, is achieved at great cost for the organism's ability to adapt to environmental changes. It is also plausible to assume that such ultra-specialization may permit rapid utilization of previously inaccessible vacant ecological niches such as caves or deep soil layers, which, in turn, may lead to rapid allopatric speciation. This hypothesis agrees with the observation that when adequately studied, endogean or troglobiont beetles occur in clusters of closely related and narrowly distributed allopatric forms. We would further reason that this ultra-specialization may be counterproductive for the long-term evolutionary success of the group, because these blind, poorly dispersing (although see Peck 1990 for notable exceptions) and narrowly distributed species are highly vulnerable to sudden changes in their environment. This implies that the majority of obligatory blind and secondarily wingless clades are expected to be short-lived in comparison to their eyed and winged relatives. The relatively young age of such ultraspecialized clades can be deduced from their geographical distribution being relatively restricted and formed by a group of allopatric taxa. This pattern can be seen in clades of endogean or troglobiont beetles (within Carabidae,
Dytiscidae, Leiodidae, Ptiliidae, Staphylinidae, Anthicidae, Curculionidae) having no significant (= intercontinental) distributional gaps among their members. Some taxa seemingly disagreeing with this pattern, like Reicheina and Anillini in Carabidae or Raymondionyminae in Curculionidae, have never been adequately demonstrated as monophyletic. Primarily wingless diplurans with some eight hundred extant blind species do not necessarily share the same blind ancestor, as implied by the discovery of the fully eyed Carboniferous Testajapyx thomasi (Kukalová-Peck, 1987). These considerations highlight the uniqueness of the likely monophyletic Leptotyphlinae consisting of blind and wingless soil-dwellers from as early as the Cretaceous, with presently some five hundred species disjunctly distributed on different continents. If these suppositions hold true, Leptotyphlinae then potentially exemplify how far in time and space such "evolutionarily committed" groups might reach.

\section{Staphylinidae, or rove beetles, the largest family of Animalia}

The addition of the former "Scydmaenidae" to the already huge family Staphylinidae makes this family the largest in Coleoptera, with 55,440 described species (extant plus extinct) recognized as valid through the end of 2007 (Newton, 2007, slightly updated), thus surpassing its only rival (Gaston, 1991), the Curculionidae, with an estimated 51,000 described species (Oberprieler et al., 2007). This makes Staphylinidae, or rove beetles, the most diverse family of Animalia.

\section{CONCLUDING REMARKS}

Our conclusion that Scydmaeninae, with relatively long elytra that cover much or all of the abdomen, are nested well within the Staphylinine Group, whose other members all have short or very short elytra exposing most abdominal segments from above (as in most other Staphylinidae), implies that long elytra in this group are a secondary development and not a retained feature of more "typical", non-staphylinid beetles with entire elytra. Indeed, the single most parsimonious tree in our combined analysis of morphological data (Fig. 11) shows short elytra (141/3) as a derived feature of the entire Staphylinine Group and longer elytra (141/1) as a synapomorphy for Scydmaeninae within that group. Scydmaenines are usually illustrated with their elytra completely covering the abdomen (e.g., O'Keefe, 2005), although when alive or preserved in liquid specimens typically have one to as many as three abdominal terga exposed (e.g., Fig. 4). Other hints that scydmaenines with long elytra may be derived from ancestors with shorter elytra include the usual sclerotization of three or more apical abdominal terga; presence of a pair of paratergites on abdominal segment VII in some taxa (e.g., Veraphis and Scydmaenus in our analysis), a characteristic staphylinid adaptation to uncovered abdominal terga; and a wing-folding pattern including a costal hinge of the type unique to Staphylinidae and closely allied groups (including Silphidae), which has been interpreted as facilitating the folding of the wings tightly under short- 
ened elytra (e.g., Hammond, 1979; Newton \& Thayer, 1995). Scydmaenine larvae are also atypical among staphylinid larvae in having urogomphi that are unarticulated or completely absent, rather than articulated as in most staphylinids and staphylinoids. However, Newton \& Thayer (1995), focusing on the Omaliine Group of staphylinid subfamilies, noted multiple examples of the secondary development of long elytra and fixed or absent larval urogomphi in Staphylinidae. Those authors also noted that the known fossil record of Staphylinidae (see discussion above) is consistent with the very early presence of short elytra (including all of the ca. 30 genera of Triassic and Jurassic age), and the subsequent appearance of forms with longer elytra, first represented by Scydmaeninae in the mid-Cretaceous. The functional significance of such apparent reversals in elytral length and loss of urogomphi has yet to be demonstrated, and is especially intriguing in the former case given the oftenassumed advantages of short elytra for exploitation of forest leaf litter and other cryptic microhabitats (e.g., Hammond, 1979).

Although the biology of scydmaenines is still poorly known overall, available evidence indicates that at least four tribes of Scydmaenitae are specialized predators of armored mites as adults and larvae, and feed by preoral digestion after penetrating the prey in diverse ways (e.g., Schmid, 1988; Molleman \& Walter, 2001). Mastigini (Mastigitae) also use preoral digestion but on softer prey, at least as larvae (De Marzo, 1983). Such predatory habits, and especially the feeding mode including preoral digestion of soft tissues of the prey followed by ingestion of the resulting liquid, are consistent with what is known of the biology of other members of the Staphylinine Group (e.g., Leschen \& Newton, 2003; Thayer, 2005), and indeed this feeding mode was cited as a common characteristic of the group when it was first proposed (Lawrence \& Newton, 1982). Oxyporinae, unique in the group in being mycophagous rather than carnivorous, also use preoral digestion of soft fungi in an exactly analogous (and probably homologous) manner (Lipkow, 1997). In contrast, adults and larvae of other Staphylinidae and other families of Staphylinoidea generally ingest solid food, although preoral digestion is known or suspected to occur within some groups including some Omaliinae, Pselaphinae and some adult Silphidae (e.g., Thayer, 2005).

ACKNOWLEDGEMENTS. A. Seago (Berkeley, USA) performed all lab work to produce five new $18 \mathrm{~S}$ rDNA sequences used in our analysis. P. Švácha (České Budějovice, Czech Republic) called our attention to the advantages of MAFFT alignment, as implemented at the web-site of Kyushu University, Japan (http://align.bmr.kyushu-u.ac.jp/mafft/online/ server/). P. Janšta (Prague, Czech Republic) advised on methodology of the Bayesian analysis. I. Ribera (Barcelona, Spain) extensively advised on logic and technicalities of DNA analysis. M.S. Caterino (Santa Barbara, USA) explaind aspects of DNA analysis. We thank M. Thayer (Chicago, USA) for the use of all photographs, taken by J.-C. Martínez as part of the Staphyliniformia TWiG subcontract to M. Thayer/FMNH in the US NSFfunded project, AToL: Assembling the Beetle Tree of Life (PIs
B. Farrell, D. Maddison, and M. Whiting, awards EF-0531768, EF-0531754, EF-0531665). Accumulation of the studied larvae and adult Staphylinoidea beetles was done through collecting efforts of numerous people, most notably M. Thayer, and with support from the National Science Foundation PEET (Partnerships for Enhancing Expertise in Taxonomy) Grant No. 0118749 to the Field Museum of Natural History (M. Thayer, Principal Investigator; A. Newton, co-Principal Investigator) and from the Field Museum of Natural History. K. McLachlan Hamilton (Ottawa, Canada) and M. Thayer reviewed this paper prior to submission. VVG also wants to acknowledge help of two individuals, who, although indirectly, significantly contributed to this project. R.G. Beutel (Jena, Germany) hosted and variously supported VVG before, during and after his 2003-04 Alexander von Humboldt Fellowship when the work on the larval part of this project was begun. A. Smetana's (Ottawa, Canada) lasting enthusiasm for rove beetles and travel stories in Asia influenced VVG to focus on this group, which eventually led to the conclusion that, much to Aleš's surprise, former "Scydmaenids" are nothing but modified Staphylinidae. Both Aleš and Rolf are cordially thanked.

\section{REFERENCES}

Beutel R.G. \& Leschen R.A.B. 2005: Phylogenetic analysis of Staphyliniformia (Coleoptera) based on characters of larvae and adults. Syst. Entomol. 30: 510-548.

Beutel R.G. \& Molenda R. 1997: Comparative morphological study of larvae of Staphylinoidea (Coleoptera: Polyphaga) with phylogenetic implications. Zool. Anz. 236: 37-67.

Caterino M.S., Shull V.S., Hammond P.M. \& Vogler A.P. 2002: Basal relationships of Coleoptera inferred from $18 \mathrm{~S}$ rDNA sequences. Zool. Scr. 31: 41-49.

Caterino M.S., Hunt T. \& Vogler A.P. 2005: On the constitution and phylogeny of Staphyliniformia. Mol. Phylogen. Evol. 34: 655-672.

Clarke D.J. \& Grebennikov V.V. 2009: Monophyly of Euaesthetinae (Coleoptera: Staphylinidae): phylogenetic evidence from adults and larvae, review of austral genera, and new larval descriptions. Syst. Entomol. 34: 346-397.

De Marzo L. 1983: Osservazioni sulla ovideposizione e sul ciclo larvale in Mastigus pilifer Kraatz (Coleoptera, Scydmaenidae). Entomologica (Bari) 18: 125-136.

FARRIS J.S. 1969: A successive approximation approach to character weighting. Syst. Zool. 18: 374-385.

Farris J.S. 1988: Hennig86. Published by the author, Port Jefferson Station, New York.

Gaston K.J. 1991: The magnitude of global insect species richness. Conserv. Biol. 5: 283-296.

Goloboff P. 1999: NONA, Version 2. Published by the author, Tucumán, Argentina.

GrebenNikov V.V. 2005: Older-instar larvae of Pseudopsinae (Coleoptera: Staphylinidae): morphological description of three genera and phylogenetic placement of the subfamily. Eur. J. Entomol. 102: 713-724.

Grebennikov V.V. \& Newton A.F. 2008: Minute larvae of Leptotyphlinae (Coleoptera: Staphylinidae): description of three genera with discussion on the monophyly and phylogenetic position of the subfamily as inferred from larval morphology. Zootaxa 1817: 49-58.

Grimaldi D. \& Engel M.S. 2005: Evolution of the Insects. Cambridge University Press, New York, xv +755 pp.

HAMmOND P.M. 1979: Wing-folding mechanisms of beetles, with special reference to investigations of Adephagan phylogeny (Coleoptera). In Erwin T.L., Ball G.E., Whitehead D.R. \& Halpern A.L. (eds): Carabid Beetles: Their Evolution, 
Natural History, and Classification. W. Junk, The Hague, pp. 113-180.

Hansen M. 1997: Phylogeny and classification of the staphyliniform beetle families (Coleoptera). Biol. Skr. 48: 1-339.

Herman L.H. 2001: Catalog of the Staphylinidae (Insecta: Coleoptera) 1758 to the end of the second millennium. Parts I-VII. Bull. Am. Mus. Nat. Hist. 265: 1-4218.

Hunt T., Bergsten J., Levkanicova Z., Papadopoulou A., St. John O., Wild R., Hammond P.M., Ahrens D., Balke M. Caterino M.C., Gómez-Zurita J., Ribera I., Barraclough T.G., Bocáková M., Bocák L. \& Vogler A.P. 2007: A comprehensive phylogeny of beetles reveals the evolutionary origins of a superradiation. Science 318: 1913-1916.

Huson D.H., Richter D.C., Rausch C., Dezulian T., Franz M. \& Rupp R. 2007: Dendroscope: an interactive viewer for large phylogenetic trees. BMC Bioinform. 8: 460.

Katoh K., Kuma K.-I., Toh H. \& Miyata T. 2005: MAFFT version 5: improvement in accuracy of multiple sequence alignment. Nucl. Acids Res. 33: 511-518.

KJER K.M. 2004: Aligned 18S and insect phylogeny. Syst. Biol. 53: 506-514.

Korte A., Ribera I., Beutel R.G. \& Bernhard D. 2004: Interrelationships of Staphyliniform groups inferred from $18 \mathrm{~S}$ and 28S rDNA sequences, with special emphasis on Hydrophiloidea (Coleoptera, Staphyliniformia). J. Zool. Syst. Evol. Res. 42: 281-288.

KunalovÁ-Peck J. 1987: New Carboniferous Diplura, Monura, and Thysanura, the hexapod ground plan, and the role of thoracic side lobes in the origin of wings (Insecta). Can. J. Zool. 65: $2327-2345$.

Lawrence J.F. \& Newton A.F. 1982: Evolution and classification of beetles. Annu. Rev. Ecol. Syst. 13: 261-290.

Lefebvre F., Vincent B., Azar D. \& Nel A. 2005: The oldest beetle of the Euaesthetinae (Staphylinidae) from early Cretaceous Lebanese amber. Cretac. Res. 26: 207-211.

LESCHEN R.A.B. \& LöBL I. 1995: Phylogeny of Scaphidiinae with redefinition of tribal and generic limits (Coleoptera: Staphylinidae). Rev. Suisse Zool. 102: 425-474.

Leschen R.A.B. \& Newton A.F. 2003: Larval description, adult feeding behaviour, and phylogenetic placement of Megalopinus (Coleoptera: Staphylinidae). Coleopt. Bull. 57: 469-493.

LIPKOw E. 1997: Zur Biologie der Ernährung, Fortpflanzung, Wirtswahl und Konkurrenzvermeidung von Oxyporus-Arten (Coleoptera: Staphylinidae). Faun. Ökol. Mitt. 7: 297-308.

MAdDison D.R., BAKer M.D. \& OBer K.A. 1999: Phylogeny of carabid beetles as inferred from $18 \mathrm{~S}$ ribosomal DNA (Coleoptera: Carabidae). Syst. Entomol. 24: 1-36.

Molleman F. \& Walter D.E. 2001: Niche segregation and canopeners: Scydmaenid beetles as predators of armoured mites in Australia. In Halliday R.B. et al. (eds): Acarology: Proceedings of the 10th International Congress. CSIRO Publications, Melbourne, Australia, pp. 283-288.

NAOMI S.-I. 1988: Comparative morphology of the Staphylinidae and the allied groups (Coleoptera, Staphylinoidea). VI. Mesothorax and metathorax. Kontyû 56: 727-738.

Newton A.F., JR. 1982: Redefinition, revised phylogeny and relationships of Pseudopsinae (Coleoptera: Staphylinidae). Am. Mus. Nov. 2743: 1-13.

Newton A.F., JR. 1998: Phylogenetic problems, current classification and generic catalog of world Leiodidae (including Cholevidae). In Giachino P.M. \& Peck S.B. (eds): Phylogeny and Evolution of Subterranean and Endogean Cholevidae (=Leiodidae Cholevinae). Proceedings of XX I.C.E., Firenze, 1996. Atti Museo Regionale di Scienze Naturali, Torino, pp. 41-178.
Newton A.F. 2007: Documenting biodiversity: how well are we doing in Staphyliniformia (Coleoptera)? Entomological Society of America poster presentation D0471. Available (ESA members only) at <http://esa.confex.com/esa/2007/ techprogram/paper_32168.htm>.

NeWton A.F. \& Franz H. 1998: World catalog of the genera of Scydmaenidae (Coleoptera). Koleopt. Rdsch. 68: 137-165.

Newton A.F., JR. \& ThaYer M.K. 1992: Current classification and family-group names in Staphyliniformia (Coleoptera). Fieldiana (Zoology) (N.S.) 67: 1-92.

Newton A.F. \& Thayer M.K. 1995: Protopselaphinae new subfamily for Protopselaphus new genus from Malaysia, with a phylogenetic analysis and review of the Omaliine Group of Staphylinidae including Pselaphidae (Coleoptera). In Pakaluk J. \& Ślipiński S.A. (eds): Biology, Phylogeny, and Classification of Coleoptera: Papers Celebrating the 80th Birthday of Roy A. Crowson. Muzeum i Instytut Zoologii PAN, Warszawa, pp. 219-320.

Newton A.F. \& Thayer M.K. 2005: Catalog of Higher Taxa, Genera and Subgenera of Staphyliniformia [online]. Chicago: Field Museum of Natural History [last updated 27 August 2005]. Available from URL: <http://www.fieldmuseum.org/ peet_staph/db_1a.html $>$.

Nixon K.C. 2002: WinClada, Version 1.0000. Published by the author, Ithaca, NY.

Oberprieler R., Marvaldi A.E. \& Anderson R.S. 2007: Weevils, weevils, weevils everywhere. Zootaxa 1668: 491-520.

O'KeEFe S.T. 2005: 11.5. Scydmaenidae Leach, 1815. In Beutel R.G. \& Leschen R.A.B. (eds): Handbook of Zoology, Vol. IV, Part 38, Coleoptera, Vol. 1: Morphology and Systematics (Archostemata, Adephaga, Myxophaga, Staphyliniformia, Scarabaeiformia, Elateriformia). De Gruyter, Berlin, pp. 280-288.

O'Keefe S., Pike T. \& Poinar G. 1997: Palaeoleptochromus schaufussi (gen. nov., sp. nov.), a new antlike stone beetle (Coleoptera: Scydmaenidae) from Canadian Cretaceous Amber. Can. Entomol. 129: 379-385.

Peck S.B. 1990: Eyeless Arthropods of the Galapagos Islands, Ecuador: composition and origin of the cryptozoic fauna of a young, tropical, oceanic archipelago. Biotropica 22: 366-381.

PoINAR G., JR. \& Brown A.E. 2004: A new subfamily of Cretaceous antlike stone beetles (Coleoptera: Scydmaenidae: Hapsomelinae) with an extra leg segment. Proc. Entomol. Soc. Wash. 106: 789-796.

Ronquist F. \& HuELSENBECK J.P. 2003: MRBAYES 3: Bayesian phylogenetic inference under mixed models. Bioinformatics 19: $1572-1574$

SCHMID R. 1988: Morphologische Anpassungen in einem Räuber-Beute-System: Ameisenkäfer (Scydmaenidae, Staphylinoidea) und gepanzerte Milben (Acari). Zool. Jb. Syst. Ökol. Geogr. Tiere 115: 207-228.

Shull V.L., Vogler A.P., Baker M.D., Maddison D.R. \& HamMOND P.M. 2001: Sequence alignment of 18S ribosomal RNA and the basal relationships of Adephagan beetles: evidence for monophyly of aquatic families and the placement of Trachypachidae. Syst. Biol. 50: 945-969.

Solodovnikov A.Yu. \& Newton A.F. 2005: Revision of the relict South African genus Arrowinus, description of its larva, and phylogenetic assessment of Arrowinini trib. n. (Coleoptera: Staphylinidae: Staphylininae). Syst. Entomol. 30: 398-441.

SpaHr U. 1981: Systematischer Katalog der Bernstein- und Kopal-Käfer (Coleoptera). Stuttg. Beitr. Naturk. (B) 80: $1-107$. 
SwOFFord D.L. 2000: PAUP*. Phylogenetic Analysis Using Parsimony (*and Other Methods). Version 4.0b1. Sinauer Associates, Sunderland, Massachusetts.

ThaYer M.K. 2000: Glypholoma larvae at last: phylogenetic implications for basal Staphylinidae? (Coleoptera: Staphylinidae: Glypholomatinae). Invertebr. Taxon. 14: 741-754.

THAYER M.K. 2005: 11.7. Staphylinidae. In Beutel R.G. \& Leschen R.A.B. (eds): Handbook of Zoology, Vol. IV, Part 38, Coleoptera, Vol. 1: Morphology and Systematics (Archostemata, Adephaga, Myxophaga, Staphyliniformia, Scarabaeiformia, Elateriformia). De Gruyter, Berlin, pp. 296-344.

Thompson J.D., Gibson T.J., Plewniak F., Jeanmougin F. \& HigGINS D.G. 1997: The ClustalX windows interface: flexible strategies for multiple sequence alignment aided by quality analysis tools. Nucl. Acids Res. 24: 4876-4882.

Wheeler Q.D. \& PaKaluk J.V. 1983: Descriptions of larval Stenichnus (Cyrtoscydmus): S. turbatus and S. conjux, with notes on their natural history (Coleoptera: Scydmaenidae). Proc. Entomol. Soc. Wash. 85: 86-97.

Zhang J.-F. 1988: The late Jurassic fossil Staphylinidae (Coleoptera) of China. Acta Entomol. Sinica 31: 79-84 [in Chinese and English].

Received May 9, 2008; revised and accepted January 7, 2009

APPENDIX 1. List of 211 morphological characters used in the analysis.

Abbreviations used for the initial sources of characters (not necessarily identically stated, but noted as modified ("mod.") if significantly re-worded): B\&M: Beutel \& Molenda (1997); C\&G: Clarke \& Grebennikov (2009); G: Grebennikov (2005); H: Hansen (1997); L\&N: Leschen \& Newton (2003); N: Newton (1982); N\&T: Newton \& Thayer (1995); S\&N: Solodovnikov \& Newton (2005); T: Thayer (2000).

\section{Larvae, body and head}

1. Frayed setae [S\&N: 99]: absent $=0$ (Fig. 15); present $=1$.

2. Relative length of setae on cranium and terga: setae of variable length: long, medium and short $=0$ (Fig. 15); setae either long or short; almost no medium setae present $=1$; all setae relatively short $=2$.

3. Trichobothria $[\mathrm{S} \& N$ : 100]: absent $=0$ (Fig. 17); present $=1$.

4. Relatively large pore-like opening dorsally on epicrania, all thoracic and abdominal terga: absent $=0$ present $=1$ (Fig. $15)$.

5. Presence, number and size of stemmata: present, six, fully developed $=0$; present, less than six or partly reduced in size $=1$ (Fig. 15); absent $=2$. [ordered].

6. Length of coronal suture (B\&M: 3 , mod.]: short, about as long as width of antennomere $1=0$; longer than 0 , about $0.3-0.5$ length of head capsule $=1$ (Fig. 3D); as long as, or longer than, half length of head capsule $=2$ (Fig. 15). [ordered]

7. Constricted neck region [S\&N: 68 , mod.]: absent $=0$; present $=1$ (Fig. 16).

8. Foramen occipital, width: wide, 0.7 and more times as wide as maximum head width $=0$ (Fig. 16); narrow, not wider than 0.5 times head width $=1$.

9. Dorsal ecdysial lines [S\&N: 69, mod.]: Y-shaped $=0$; lyriform $=1$ (Fig. 15).

10. Nuchal carina in posterior part of head: absent $=0$; present $=$ 1 (Fig. 16)

11. Ventral arms of nuchal carina: arms directed anteromedially $=0$; arms directed medially $=1$ (Fig. 16).

12. Anteriorly directed large sclerotized tooth of ventral wall of head capsule: absent $=0$; present $=1$ (Fig. 16).
13. Posterior tentorial pits [S\&N: 72, mod.]: much (more than 5 times) longer than wide $=0$; short, rounded to elongate $=1$ (Fig. 16).

14. Posterior tentorial arms: wide and short, not more that 10 times as long as wide $=0$; extremely thin, thread-like and more than 20 times as long as wide $=1$ (Fig. 15).

15. Origin and shape of tentorial bridge: from posterior tentorial pits, wide $=0$; from posterior tentorial arms, very narrow or, apparently, absent $=1$ (Fig. 15).

16. Attachment of anterior tentorial arms to dorsum of head capsule: indistinct and/or rounded, not transverse $=0$ (Fig. 15); markedly transverse, extending mesally from dorsal mandibular condyle $=1$.

17. Ventral ecdysial lines [L\&N: 41]: absent $=0$; present $=1$ (Fig. 16).

18. Shape of ventral ecdysial lines [S\&N: 70]: linear, extending from base of head to vicinity of posterior tentorial pits $=0$; $\mathrm{Y}$-shaped, branching in vicinity of posterior tentorial pits and extending between maxillary foramina $=1$ (Fig. 16).

19. Oblique hypostomal ridges on ventral surface of head capsule near maxillary foramina: absent $=0$ (Fig. 16); short, not longer than length of cardo $=1$; long, about twice longer than length of cargo $=2$. [ordered]

20. Labrum [B\&M: 7, mod.]: separated from clypeus by distinct suture visible on all length $=0$; partly fused to clypeus with the suture visible only laterally $=1$; firmly fused to clypeus forming a nasale $=2$ (Fig. 15). [ordered].

21. One or two lateral sclerites on each side of labrum near its articulation/fusion to clypeus: absent $=0$ (Fig. 15); present $=$ 1.

22. Anterior edge of labrum/nasale [L\&N: 31, mod.]: not toothed or serrate $=0$; toothed or serrate $=1$ (Fig. 19).

23. Median tooth on labrum or nasale: absent $=0$; present $=1$ (Fig. 19).

24. Tormae (not illustrated): absent $=0$; present $=1$.

25. Main sensory appendage on antenna; its position with respect to articulation of apical antennomere [S\&N: 77, mod.]: anterior $/$ mesal $=0$ (Fig. 15$)$; ventral $=1$; dorsal $=2$; posterior $/$ lateral $=3$; apical $=4$.

26. Shape of the main sensory appendage of antenna [S\&N: 78 . mod]: bulbous, with convex sides $=0$ (Fig. 20); very elongate and narrow, along much of its length parallel-sided $=1$.

27. Length of sensory appendage: as long as or shorter than width of penultimate antennomere $=0$ (Fig. 20); longer than the width of penultimate antennomere $=1$.

28. Shape of ultimate antennomere: of regular shape or slightly shortened, ratio length to width $1.5-2.5=0$ (Fig. 20); absent, deformed, or shortened, ratio length to width 1 and less $=1$; markedly elongate, ratio length to width more than $3=2$.

29. Membrane connecting basal antennomere with head capsule: absent or short, not much larger that membrane between antennomeres 2 and $3=0$ (Figs 25, 29); much larger than membrane between antennomeres 2 and 3 , about as long as antennomere $1=1$.

30. Basal antennomere [S\&N76]: not constricted or interrupted by membrane; antennae clearly three-segmented $=0$; constricted by a sclerotized ring; antennae appearing foursegmented. $=1$; separated by membranous ring or constriction into two pseudo-segments, antennae appearing foursegmented $=2$ (Fig. 20).

31. Length of antennae: shorter than $1 / 3$ of length of head capsule $=0$; longer than half length of, but shorter than whole length, of head capsule $=1$ (Fig. 15); about as long as head capsule $=2$; markedly longer than head capsule $=3$ (Fig. 22) . [ordered]. 


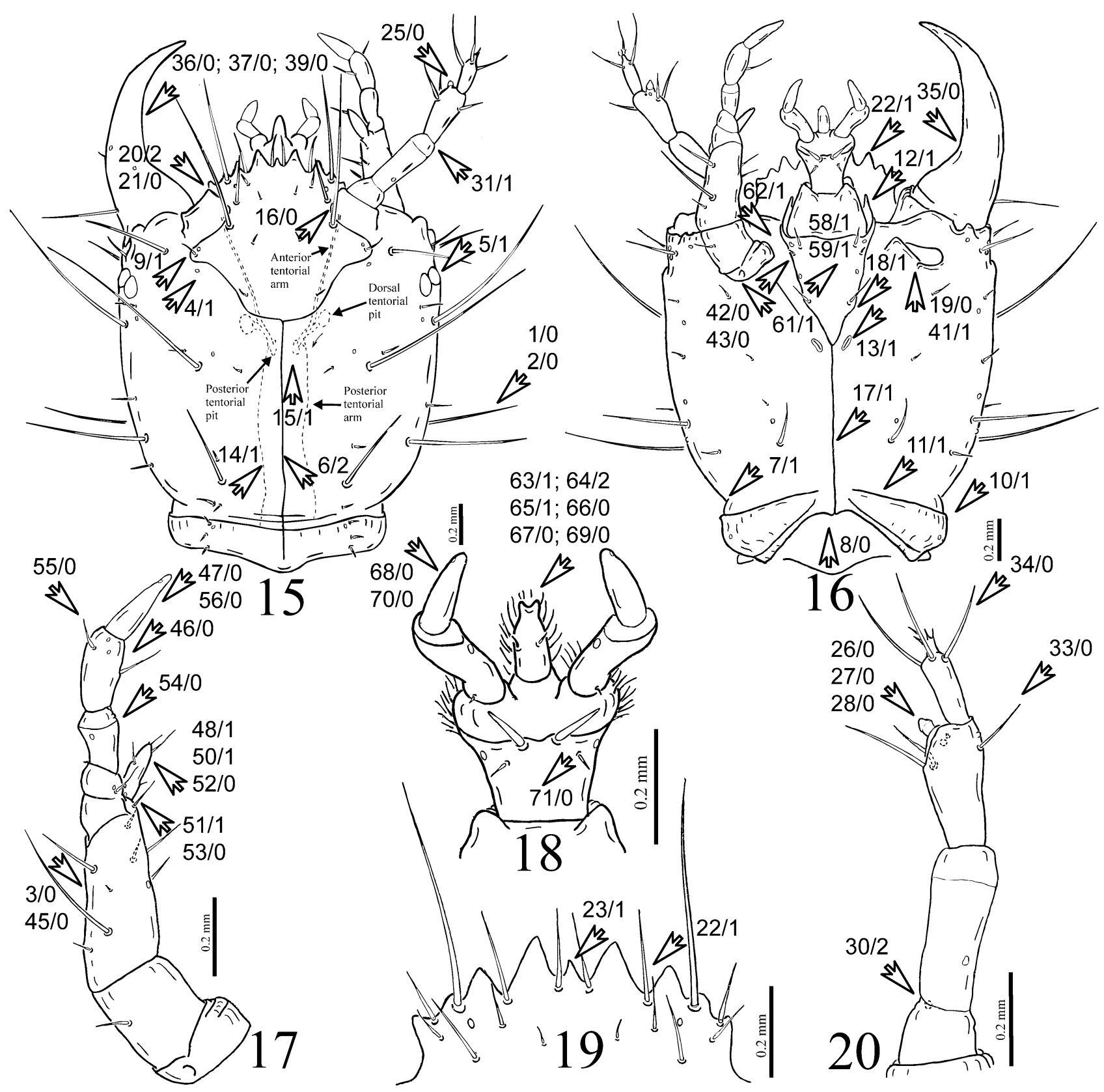

Figs 15-20. Larva of Platydracus maculosus (Staphylininae), details. 15, 16 - head (right mandible, left antenna and left maxilla omitted), dorsal (15) and ventral (16); 17 - right maxilla, ventral; 18 - labium, ventral; 19 - nasale, dorsal; 20 - right antenna, dorsal. Numbered arrows correspond to character number/state in Appendix 1.

32. Seta or setae on first (basal) antennomere: absent $=0$ (Fig. 28 ; present $=1$.

33. Number of long setae in apical half of second (penultimate) antennomere: three $=0$ (Fig. 20); more than three $=1$ (Fig. 28).

34. Number of long setae in apical half of third (ultimate or apical) antennomere; not including a single non-articulated setalike sensory structure: three $=0$ (Fig. 20 ); more than three $=$ 1.

35. Mandibular mola: absent $=0$ (Fig. 16); present, small, maximum 2 -3 times wider than mandible at middle $=1$; present, large, 5-7 times wider than mandible at middle $=2$. [ordered].

36. Mandibles, mesal dentition [S\&N: 79, mod.]: absent, without preapical teeth $=0$ (Fig. 15); present, with 1-3 preapical teeth $=1$.
37. Mandibles, single large tooth on mesal surface directed markedly dorsally: absent $=0$ (Fig. 15); present $=1$.

38. Mandibles, symmetry [T: 51, mod.]: symmetrical or almost symmetrical $=0$ (Fig. 26); markedly asymmetrical $=1$.

39. Mandibles, mesal serration (T: 53 , mod.]: absent completely $=0$ (Fig. 15); present, at least partly $=1$ (Fig. 26).

40. Mandibles, shape: relatively straight and slightly curved, apices when open directed anteriorly $=0$; markedly curved, apices when open directed almost mesally $=1$ (Fig. 24).

41. Articulation of maxillae: through large membranous articulating area $=0$ (Fig. 27); through condyle, membranous articulated area reduced or absent $=1$ (Fig. 16).

42. Cardo, size of sclerotized part compared to the base of stipes: about as wide as, or wider than, base of stipes $=0$ (Fig. 16); reduced in size, markedly narrower than base of stipes $=$ 1. 
43. Cardo, transverse ridge on its sclerotized part: absent $=0$ (Fig. 16); present $=1$.

44. Stipes, shape (not considering mala) whether characteristically straight-sided and narrowed apicad: not narrowed apicad, if narrowed than not straight-sided $=0$ (Fig. 27); characteristically straight-sided and narrowed apicad $=1$.

45. Lateral edge of stipes, whether with constriction or not: without obvious constriction $=0$ (Fig. 17); with constriction at middle $=1$.

46. Maxillary palpomere 2, shape: straight $=0$ (Fig. 17); markedly bent $=1$ (Fig. 27).

47. Maxillary palpomere 3, length and shape [L\&N34, mod.]: relatively stout (not more than 8 times as long than wide) and rigid $=0$ (Fig. 17); very slender (10 and more times longer than wide) with $1-2$ weak deflection points $=1$ (Fig. 27).

48. Galea and lacinia: fully or partly separate $=0$; completely fused forming mala $=1$ (Figs 17, 27).

49. Dense setal brush on outer lobe of divided mala (galea) (not illustrated): absent $=0$; present $=1$.

50. Galea and lacinia (or mala), shape: wide and stout or, if narrow apically, then widening to base $=0$ (Fig. 27); fingerlike, parallel-sized along its length $=1$ (Fig. 17).

51. Galea and lacinia (or mala), articulation to stipes: fused to stipes $=0$; articulated to stipes $=1$ (Fig. 17).

52. Galea and lacinia (or mala), size: large, its length is equal to, or longer than, apical width of stipes $=0$ (Figs 17, 27); absent or small, not longer than apical width of stipes $=1$.

53. Galea and lacinia (or mala), position of attachment to stipes: attached to mesal surface of stipes, clearly protruding mesally $=0$ (Fig. 17); attached to dorso-mesal surface of stipes; not protruding mesally $=1$.

54. First (basal) maxillary palpomere (one apicad of maxillary palpifer): without setae $=0$ (Fig. 17); with setae $=1$ [parsimoniously uninformative and deactivated].

55. Second (penultimate) maxillary palpomere: with two setae $=$ 0 (Fig. 17); with more than two setae $=1$.

56. Third (apical) maxillary palpomere: without setae $=0$ (Fig. 17); with setae $=1$.

57. Third (apical) maxillary palpomere: entire $=0$; subdivided by membrane into two pseudosegments $=1$ (Fig. 27).

58. Ventral side of head [S\&N: 71, mod.]: with free submentum $=0$; with submentum fully fused to cranium $=1$ (Fig. 16).

59. Ventral side of head [S\&N: 71, mod.]: with free mentum $=$ 0 ; with mentum fused to submentum and both fused to head capsule $=1$ (Fig. 16).

60. Mentum (not illustrated): with triangular or sub-quadrate sclerite bearing two pairs of setae $=0$; mainly membranous, with transverse two-setose sclerite $=1$.

61. Maxillary foramina anteriorly: open $=0 ; \operatorname{closed}=1$.

62. Maxillary foramina mesally: open $=0$; closed $=1$ (Fig. 16).

63. Ligula, presence: absent $=0$ (Fig. 27); present $=1$ (Fig. 18).

64. Ligula, shape: variously shaped, not sclerotized or digitiform $=0$; digitiform, sclerotized, as long as wide and articulated to membranous prementum $=1$; digitiform, sclerotized, longer than wide and articulated to membranous prementum $=$ 2 (Fig. 18).

65. Ligula, width at apex: wide, markedly wider than basal labial palpomere $=0$; narrow, as wide as, or narrower than, basal labial palpomere $=1$ (Fig. 18).

66. Ligula, whether broadly bilobed at apex: straight, pointed or rounded, not bilobed $=0$ (Fig. 18); broadly bilobed at apex $=$ 1.

67. Ligula, length: long, about as long as basal labial palpomere $=0$ (Fig. 18); short, about as long as width of basal labial palpomere $=1$.
68. Labial palpomere 2: rigid and wide; not more than 6 times as long as its basal width $=0$ (Fig. 18); narrow and elongate; about 8 times as long as its basal width $=1$.

69. Long membranous and microsetose anterior projection of ligula: absent $=0$ (Fig. 18); present $=1$.

70. Apical labial palpomere: complete $=0$ (Fig. 18); subdivided by membrane into two pseudosegments $=1$.

71. Ventral sclerite of prementum [L\&N: 35]: entire $=0$ (Fig. 18 ); at least partly (apically) divided along midline $=1$.

\section{Larvae, thorax}

72. Pronotum $[\mathrm{S} \& N$ : $84, \bmod$.$] : without posterior carina =0$ (Fig. 21); with posterior carina $=1$.

73. Cervicosternum [S\&N: 87]: transverse, anterior to proepisterna $=0$ (Fig. 23); triangular, apex extends posteriorly between proepisterna $=1$.

74. Meso- and metatergum [S\&N: 85, mod.]: without posterior carina $=0$ (Fig. 21); with posterior carina $=1$.

75. Longest seta on trochanter, length (not illustrated): two and more times longer than width of trochanter $=0$; one and half times as long as, or shorter than, width of trochanter $=1$.

76. Longest seta on legs, location (not illustrated): on trochanter $=0$; on femur $=1$; no clearly defined longest seta $=2$.

77. Tibiotarsus, shape [L\&N 46, mod.]: normal (fairly stout) = 0 ; entirely styliform $=1$ (Fig. 22); abruptly styliform in apical half $=2$.

78. Tibiotarsus, width and presence of two stout spines at middle: tibiotarsus at middle not wider than at base, without two spines $=0$ (Fig. 22); tibiotarsus at middle widened, markedly wider than at base, with two spines $=1$.

79. Setae at apex of tibiotarsus: short, as long as or shorter than claw's width at base $=0$ (Fig. 22); long, about as long as length of claw $=1$.

\section{Larvae, abdomen}

80. Abdominal terga [S\&N: 93, mod.]: undivided = 0 (Fig. 21); medially divided by membranous area $=1$.

81. Abdominal sterna [S\&N: 94, mod.]: undivided $=0$; medially divided by membranous area $=1$ (Fig. 23 ).

82. Elongate and latero-posteriroly directed tube-like process on each side of abdominal segment IX terminated by long seta: absent $=0$ (Fig. 21); present $=1$.

83. Openings of abdominal (and thoracic) spiracles: not or only slightly elevated compared to body surface $=0$ (Fig. 22); markedly elevated and located on apices of tube-like projections $=1$.

84. Abdominal laterotergites [S\&N: 95, mod.]: separate laterosclerites absent, apparently fused with tergum encircling spiracles $=0$; one pair present $=1$ (Fig. 22); two (sometimes 3) pairs present on at least segments II-VI $=2$; absent, not fused with tergum, spiracles not encircled $=3$.

85. Urogomphi: absent $=0$ (Fig. 21$)$; present $=1$.

86. Urogomphi, articulation to tergum IX (not illustrated): indistinctly articulated, apparently not movable $=0$; distinctly articulated $=1$.

87. Long apical seta on urogomphi (not illustrated): absent $=0$; present $=1$.

88. Number of segments of urogomphi [T: 118] (not illustrated): two $=0$; one $=1$.

89. Urogomphi, relative length (not illustrated): about two times as long as, or longer than, tergum VIII $=0$; about as long as, slightly longer, or shorter than, tergum VIII $=1$.

\section{Adults, head}

90. Dorsal tentorial pits (or a single pit, if fused) [C\&G: 1]: absent $=0$; present, visible externally as depressions or distinct pits $=1$ (Fig. 33). 


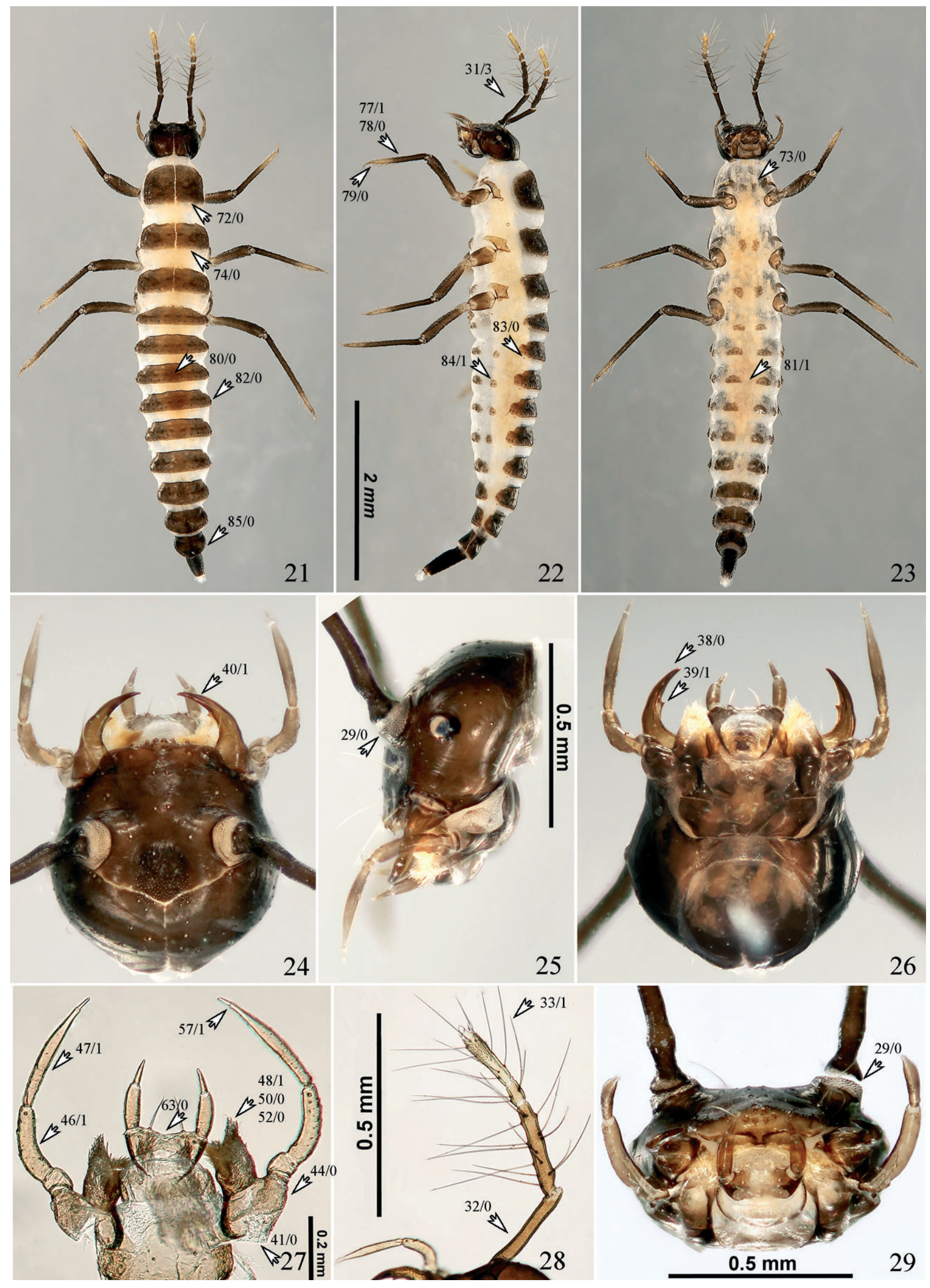

Figs 21-29. Larva of Palaeostigus bifoveolatus (Scydmaeninae), details. 21-23 - habitus, dorsal (21), lateral (22) and ventral (23); 24-26 - head, dorsal (24), lateral (25) and ventral (26); 27 - maxillae and labium, ventral; 28 - left antenna, ventral; 29 - head, frontal. Numbered arrows correspond to character number/state in Appendix 1. 
91. Interantennal pits [C\&G: 2]: absent $=0$ (Fig. 33); present $=$ 1.

92. Lateral neck constriction: present $=0$ (Fig. 33 ); absent $=1$.

93. Dorsal transverse nuchal impression [C\&G: $3 ; \mathrm{N}: 8]$ : present $=0$ (Fig. 34); absent $=1$.

94. Epistomal (=frontoclypeal) suture [C\&G: 7; L\&N: 3]: present $=0$ (Fig. 33); absent $=1$.

95. Antennal insertion in dorsal view [C\&G: 8]: concealed under a ridge $=0$; more or less exposed $=1$ (Fig. 33).

96. Compound eyes: absent $=0$; present $=1$ (Fig. 34).

97. Antennal insertion, location in relation to anterior margin of eye [C\&G: 9 , mod.]: at, or anterior to, anterior margin of eye $=0$; posterior to anterior margin of eye $=1$ (Fig. 34).

98. Gular sutures, whether present and complete [C\&G: 10, mod.; L\&N: 7, mod.]: present, complete $=0$; present, incomplete either anteriorly or posteriorly $=1$ (Fig. 35); absent $=2$. [ordered].

99. Gular sutures, whether fused or separate [C\&G: 10 , mod; L\&N: 7, mod.]: completely separate $=0$ (Fig. 35); fused for more than half of their length $=1$; fused medially (less than $1 / 3$ length), diverging anterad and posterad $=2$.

100. Ommatidia structure [C\&G: 11]: facets hexagonal and flat, eye surface smooth $=0$ (Fig. 33); facets round and strongly convex, eye surface botryoidal $=1$.

101. Tentorial bridge [C\&G: 13] (not illustrated): present $=0$; absent $=1$ [parsimoniously uninformative and deactivated].

102. Corporotentorium [C\&G: 15; ex N\&T: 24] (not illustrated): present, split $=0$; absent $=1$; present, fused $=2$.

103. Antennal club [C\&G: 16; L\&N: 1]: absent $=0$ (Fig. 30); present $=1$

104. Number of antennomeres in antennal club (in females if dimorphic) [C\&G: 17]: zero, club absent $=0$ (Fig. 30); two or three $=1$; four or more $=2$.

105. Labrum, shape from above [S\&N: 11, mod.]: subquadrate to moderately transverse (up to $1.5 \mathrm{X}$ ) $=0$; strongly transverse ( 2 and more $\mathrm{X}$ as wide as long) $=1$ (Fig. 33).

106. Labrum, whether bilobed: not bilobed $=0$; bilobed $=1$ (Fig. 33).

107. Anterior margin of labrum [C\&G: 22]: sclerotized, smooth $=0$ (Fig. 33); sclerotized, denticulate or serrate $=1$; with transparent apical membrane $=2$.

108. Mandibular proportions [C\&G: 25, mod.]: mandibles less than three times as long as maximal width $=0$ (Fig. 37); mandibles between three and five times as long as maximal width $=1 ;$ mandibles more than five times as long as maximal width $=2$. [ordered].

109. Mandibles in apposition [C\&G: 26, mod.]: apices fully exposed $=0$ (Fig. 30); apices concealed beneath labrum $=1$.

110. Inner edge of mandibles [C\&G: 27 , mod.]: smooth $=0$ (Fig. 37); serrate $=1$.

111. Preapical mandibular teeth (in females, if dimorphic) [C\&G: 28; N\&T: 31 , mod.]: asymmetrical in number $=0$; symmetrical in number $=1$ (Fig. 37).

112. Maximum number of preapical teeth on inner margin of mandibles [C\&G: 29; N\&T: 32]: two and more $=0$ (Fig. 37); one $=1$; zero $=2$.

113. Mandibular prostheca [C\&G: 31; L\&N: 4]: present $=0$ (Fig. 37); absent $=1$.

114. Mandibular molar lobe [S\&N: 13; C\&G: $32, \mathrm{~L} \& \mathrm{~N}: 5$, mod.]: present, contiguous, well developed, with sclerotized microsculpture $=0$; present, contiguous, weakly developed, with microtrichiae $=1$; absent $($ non-contiguous $)=2$ (Fig. 37). [ordered]

115. Apical unarticulated spine of lacinia [C\&G: 34 ; N\&T: 38 , mod.]: absent $=0$ (Fig. 39); present $=1$.
116. Maxillary palpomere III, length [C\&G: 37, mod.]: two thirds or less than palpomere II $=0$; subequal to palpomere II $=1$ (Fig. 35); longer than palpomere II $=2$.

117. Maxillary palpomere IV [C\&G: 38; L\&N: 6]: welldeveloped, fully sclerotized, similar in width to palpomere III $=0$ (Fig. 35); about half the width of palpomere III $=1$; minute, hyaline, not more that $1 / 4$ width of palpomere III $=2$; absent $=3$. [ordered].

118. Lateral premental lobes ("paraglossae" of some authors): absent $=0$; present $=1$ (Fig. 38).

119. Medial premental lobes ("glossae" of some authors; not to confuse with lateral premental lobes or "paraglossae" of some author: present $=0$ (Fig. 38); absent $=1$.

120. Insertion and proximity of labial palps [C\&G: 43 , mod.]: separated by less than maximum width of basal palpomere = 0 ; separated by more than maximum width of basal palpomere $=1$ (Fig. 38).

121. Labial palpomere II [C\&G: 45 , mod.]: unmodified, subequal in width to palpomere $\mathrm{I}=0$; strongly expanded, subglobular or subfusiform $=1$ (Fig. 38).

122. Labial palpomere III [C\&G: 46, mod.; S\&N: 18, mod.]: about as wide as penultimate palpomere, well sclerotized $=0$; about half as wide as penultimate palpomere, well sclerotized $=1$; acicular, hyaline, about third or less as wide as penultimate palpomere $=2$ (Fig. 38); moderately to strongly expanded apically, subtriangular $=3$.

123. Mentum [C\&G: 48]: subquadrate or elongate $=0$; transverse (more than 1.5 times as wide as long) $=1$ (Fig. 38).

124. Mentum, number of macrosetae (those two and more times longer than surrounding ones, if any) [S\&N: 19, mod.]: one pair $=0$; two pairs $=1$; three pairs or more $=2$ (Fig. 35); absent $=3$.

125. Submentum and gula [C\&G: 50; N\&T: 20, mod.]: separated by internal ridge anterior to posterior tentorial pits $=0$; fused $=1$ (Fig. 35).

\section{Adults, thorax}

126. Cervical sclerites [C\&G: 52 , mod.; L\&N: 8 , mod.]: large $=$ 0 ; small and very slender $=1$; absent $=2$ (Fig. 33). [ordered].

127. Anteprosternal plates [S\&N: 20, mod.]: absent $=0$ (Fig. 40 ); present as pair (small and separated to large and contiguous) $=1$.

128. Pronotal marginal carina [C\&G: 53 mod.; S\&N: 21, 22. mod.]: reaching anterolateral margin without meeting notosternal suture $=0$; not reaching anterolateral margin, fused to notosternal suture $=1$; obsolete anteriorly, not meeting anterolateral margin or notosternal suture $=2$ (Fig. $31)$.

129. Inferior hypomeral marginal carina [C\&G: 55]: present, complete or incomplete $=0$ (Fig. 40); absent $=1$.

130. Pronotum, front angles [S\&N: 23]: not produced anterad of anterior margin of prosternum $=0$ (Fig. 40 ); produced anterad of anterior margin of prosternum $=1$.

131. Pronotal hypomeron [S\&N: 24]: not inflexed, visible in lateral view $=0$ (Fig. 31 ); inflexed, mostly not visible in lateral view, except postcoxal process $=1$.

132. Pronotal postcoxal process of hypomeron [S\&N: 25]: well developed and sclerotized similarly to rest of hypomeron $=0$ (Fig. 40); variously developed but weakly sclerotized, translucent, \pm flexible $=1$; absent $=2$. [ordered].

133. Pronotosternal suture [S\&N: 26 ; C\&G: 56 ; L\&N: 9 , mod.]: present, complete, distinctly membranous $=0$; present, \pm complete as fine groove or carina, not membranous $=1$; absent, or very incomplete and evident only posteriorly near coxal cavity $=2$ (Fig. 40). [ordered]. 

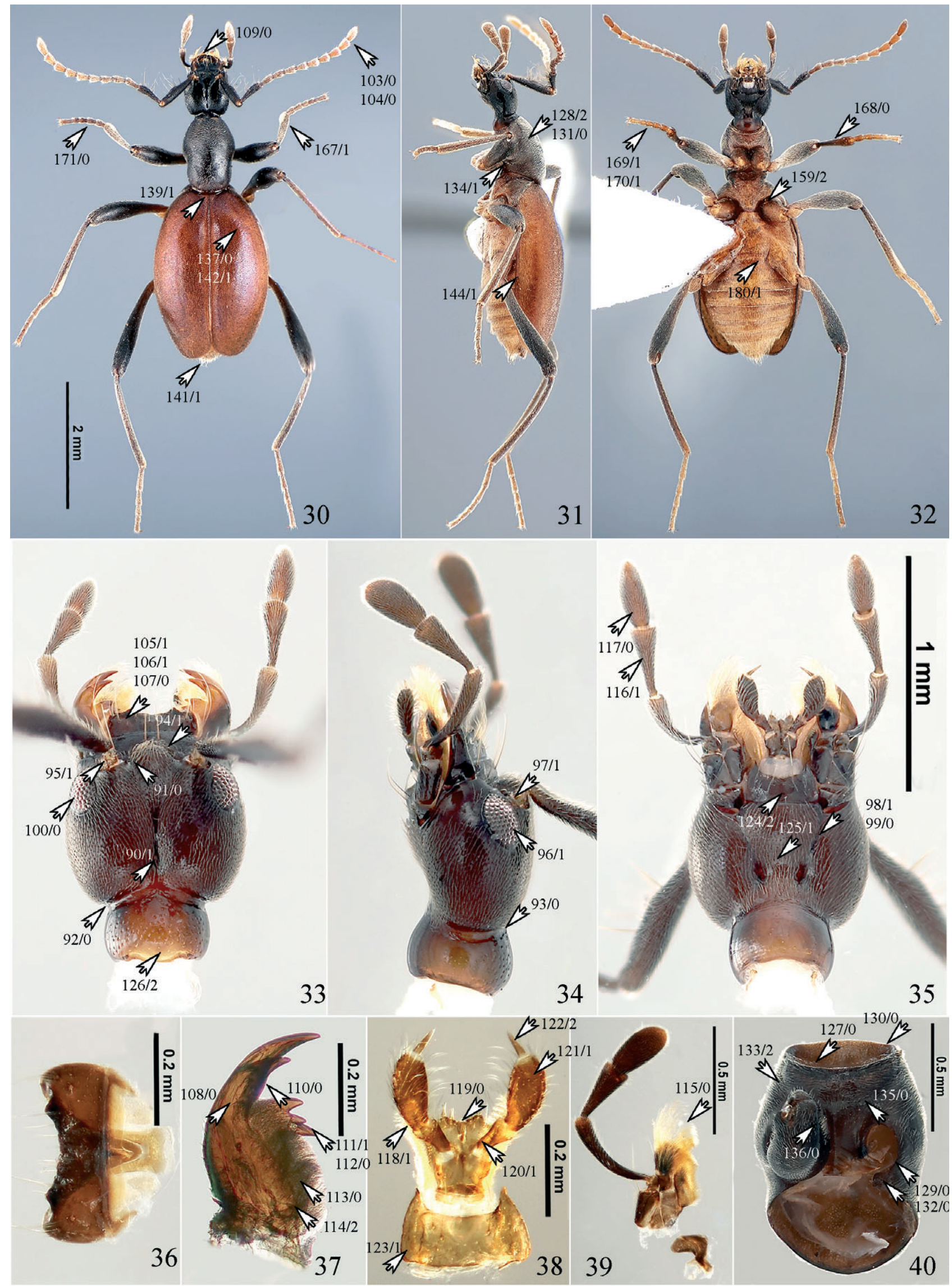

Figs 30-40. Adult of Palaeostigus bifoveolatus (Scydmaeninae), details. 30-32 - habitus, dorsal (30), lateral (31) and ventral (32); 33-35 - head, dorsal (33), lateral (34) and ventral (35); 36 - labrum, dorsal; 37 - left mandible, dorsal; 38 - labium, ventral; 39 right maxilla, ventral; 40 - prothorax, ventral (legs omitted, except right coxa). Numbered arrows correspond to character number/state in Appendix 1. 
134. Protrochantin in lateral view [C\&G: 57; L\&N: 10]: exposed $=0$; concealed $=1$ (Fig. 31$)$.

135. Anteprocoxal lobes of prosternum [C\&G: 60]: absent $=0$; present $=1$

136. Procoxal mesial surface [C\&G: 61; L\&N: 11]: smooth, without carina-delimited groove $=0$ (Fig. 40); excavate, with carina-delimited groove $=1$.

137. Pronotum and/or elytra [C\&G: 62; N: 1]: with longitudinal carinae or costae $=0$ (Fig. 30); without longitudinal carinae or costae $=1$.

138. Antemesosternal sclerite or sclerites [C\&G: 64; N: 33] absent $=0$ (Fig. 41); present $=1$.

139. Scutellar shield in dorsal view, more than half of it [C\&G: $65]$ : exposed $=0$; concealed by pronotum (when pronotum in retracted position $)=1$ (Fig. 30$)$.

140. Scutellum, transverse carina/ae, even if incomplete [S\&N: 35 , mod.]: with one transverse carina $=0$; with two transverse carinae $=1$; without transverse carinae $=2$ (Fig. 43).

141. Elytral length relative to abdomen, viewed from above: entire (abdomen completely concealed $)=0$; slightly truncate (1-2 terga exposed) $=1$ (Fig. 30$)$; strongly truncate (3-5 terga exposed $)=2$; short $(6-7$ terga exposed $)=3$.

142. Elytral striation, whether present or not [C\&G: 66, mod.; L\&N: 22, mod.]: present, either striae, punctures, or both $=0$; absent $=1$ (Fig. 30).

143. Elytral striation [C\&G: 66, mod.; L\&N: 22, mod.] (not illustrated): represented by punctures only $=1$; continuously impressed and punctured $=2$.

144. Elytral epipleural keel [C\&G: 67; L\&N: 23]: present $=0$; absent $=1$ (Fig. 31).

145. Metathoracic wing: present, apparently functional $=0$; extremely reduced or absent, non-functional $=1$ (Fig. 43).

146. Wing folding pattern, costal hinge [N\&T: 74, mod.] (not illustrated): absent $=0$; present $=1$.

147. Wing folding pattern [N\&T: 74, mod.] (not illustrated) wing folding symmetrical (with about $2 / 3$ overlap) $=0$; wing folding asymmetrical (with full overlap) $=1$.

148. Anal lobe of wing [N\&T: 75, mod.] (not illustrated): present $=0 ;$ absent $=1$

149. Anal lobe of wing [N\&T: 75 , mod.] (not illustrated): large $(>1 / 2$ wing width), with small or no fringe $=0$; small $(<1 / 2$ wing width), with long fringe $=1$.

150. Wing venation, vein MP3 [N\&T: 76, mod.] (not illustrated): absent $=0$; present $=1$.

151. Wing venation, vein MP4 [N\&T: 76, mod.] (not illustrated): absent $=0$; present $=1$.

152. Mid-lateral elytral binding patch [C\&G: 70; H: 66] (not illustrated): absent $=0$; present $=1$.

153. Baso-lateral elytral binding patch binding with metepimeron [C\&G: 71] (not illustrated): present $=0$; absent $=1$.

154. Transverse mesanepisternal carina, even if incomplete (“Anepisternum" by Naomi 1988: fig. 4A) [C\&G: 72, mod.]: absent $=0$; present $=1$ (Fig. 42).

155. Carina delimiting prepectus (anterior part of the ventral mesothorax delimited by a transverse carina from the main part of the mesothorax; Naomi, 1988) from metanepisternum: present $=0$ (Fig. 42); absent $=1$.

156. Mid-longitudinal carina of mesoventrite [C\&G: 73; N: 34] absent $=0$ (Fig. 41); present $=1$.

157. Mesothoracic anapleural suture (Naomi 1988: fig. 4C) [C\&G: 76; L\&N: 13, mod.]: present at least anteriorly and posteriorly $=0$; absent $=1$ (Fig. 41 ).

158. Mesotrochantin in lateral view [C\&G: 78; L\&N: 12]: exposed $=0 ;$ concealed $=1$ (Fig. 41$)$
159. Mesocoxae [C\&G: 79, mod.]: contiguous $=0$; narrowly separated by third or less coxal width $=1$; widely separated by half or more coxal width $=2$ (Fig. 32).

160. Mesocoxal separation formed mainly by [C\&G: 79, mod.]: mesoventral posterior process $=0$; metaventral anterior process $=1$; them both (or processes fused) $=2$ (Fig. 41) .

161. Meso-metaventral suture dorsad of mesocoxae [C\&G: 80]: present $=0$; absent $=1$ (Fig. 41).

162. Mesal posterior lobes of metaventrum [C\&G: 81, mod.]: absent $=0$; present $=1$ (Fig. 41$)$.

163. Mesendosternites, whether elbowed or straight [C\&G: 82 , mod.]: elbowed $=0$; straight $=1$ (Fig. 44).

164. Mesendosternites, their apices [C\&G: 82, mod.]: without apical muscle disk, free $=0$ (Fig. 44); with apical muscle disk, free $=1$; partly fused to pleural phragma $=2$.

165. Stem of metendosternite [C\&G: 83; L\&N: 14]: present $=0$ (Fig. 44); absent $=1$.

166. Tibial spurs at least half as long as tibial width [C\&G: 84]: present $=0$ (Fig. 51); absent $=1$.

167. External protibial spines [C\&G: 85]: present $=0$; absent $=$ 1 (Fig. 30).

168. Protibial internal setae, whether forming comb-like rows (except, or in addition to, single row at tibial apex) [S\&N: 37, mod.]: not forming rows $=0$ (Fig. 32); forming single longitudinal row $=1$; forming several to many longitudinal, oblique, or transverse rows $=2$.

169. Protarsal spatulate setae in males [S\&N: 38 , mod.]: absent $=0$; present $=1$ (Fig. 32).

170. Protarsal spatulate setae in females [S\&N: 38 mod.]: absent $=0$; present $=1$ (Fig. 32).

171. Protarsi [C\&G: 86]: 5-segmented, all tarsomeres articulated $=0$ (Fig. 30$) ; 5$-segmented, tarsomeres 1 and 2 connate $=1$; 4-segmented $=2 ; 3$-segmented $=3$.

172. Mesotarsi [C\&G: 87]: 5-segmented, all tarsomeres articulated $=0$ (Fig. 51); 5-segmented, tarsomeres 1 and 2 connate $=1 ; 4$-segmented $=2 ; 3$-segmented $=3$.

173. Metatarsi [C\&G: 88, mod.]: 5-segmented, all tarsomeres articulated $=0$ (Fig. 51); 5-segmented, tarsomeres 1 and 2 connate $=1 ; 4$-segmented $=2 ; 3$-segmented $=3$.

174. Ventral process projecting between tarsal claws [C\&G: 89]: absent $=0$; present, acutely rounded or somewhat frayed apically $=1$ (Fig. 51).

175. Empodial setae [C\&G: 90]: present, one pair $=0$ (Fig. 51); absent $=1$.

176. Tarsal claws [C\&G: 91]: simple, not toothed or serrate $=0$ (Fig. 51); toothed basoventrally $=1$ [parsimoniously uninformative and deactivated].

177. Metacoxae, length measured along body's axis [C\&G: 92, mod.]: narrowly transverse (lateral part less than half as long as longest part) $=0$; widely transverse (lateral part half or more as long as longest part) $=1$; subconical $=2$ (Fig. 41).

178. Posterior face of metacoxae [C\&G: 93; L\&N: 16]: oblique $=0$; vertical $=1$ (Fig. 41).

179. Mesal articulations of metacoxae with metaventrum [C\&G: 94]: subcontiguous (less than $1 / 10$ of metathoracic width), close to mesal edges of metacoxae $=0$; widely separated (more than 1/10 of metathoracic width) and on ventral side of metacoxae $=1$ (Fig. 41).

180. Metacoxae, whether contiguous or not [C\&G: 95]: contiguous or very narrowly separated (less than $1 / 10$ of metaventral $\mathrm{w}=0$; widely separated (more than $1 / 6$ of metaventral width) $=1$ (Fig. 32).

\section{Adults, abdomen}

181. Wing folding setal patches on tergite IV [C\&G: 97 ; L\&N: 18 , mod.]: present $=0$; absent $=1$ (Fig. 43 ). 


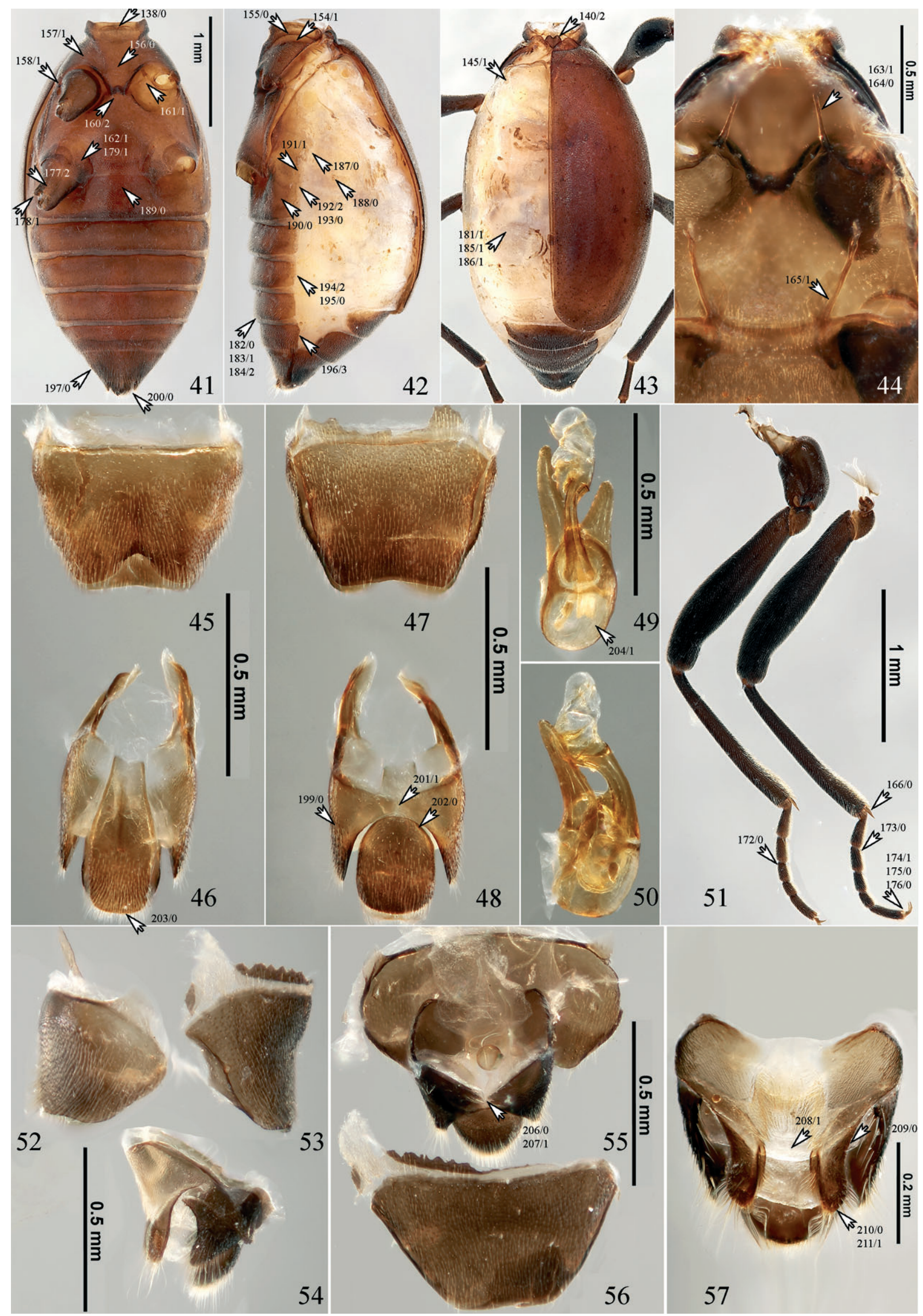

Figs 41-57. Adult of Palaeostigus bifoveolatus (Scydmaeninae), details. 41-43 - pterothorax and abdomen, ventral (41), lateral (42) and dorsal (43); 44 - pterothorax dorsal showing mes- and metendosternites; 45-48 - male genital segments, ventral (45, 46) and dorsal (47, 48); 49, 50 - aedeagus, dorsal (49) and lateral (50); 51 - hind- and middle legs; 52-57 - female genital segments, lateral $(52-54)$, dorsal $(55,56)$ and ventral $(57)$. Numbered arrows correspond to character number/state in Appendix 1. 
182. Attachment of abdominal intersegmental membrane to preceding sternum [C\&G: 98; L\&N: 20]: apical $=0$ (Fig. 42); preapical $=1$.

183. Intersegmental membrane sclerites [C\&G: 99 , mod.; $S \& N$ : 55 , mod.]: absent $=0$; present $=1$ (Fig. 42).

184. Shape of intersegmental membrane sclerites [C\&G: 99, mod.; S\&N: 55, mod.]: quadrangular or hexagonal, occupying $>80 \%$ membrane surface $=0$; triangular or odd-angular, occupying $>70 \%$ membrane surface $=1$; irregularly shaped, rounded, occupying $<70 \%$ membrane surface $=2$ (Fig. 42 ).

185. Anterior transverse basal carina on most of abdominal tergites III-VII [C\&G: 100, mod.]: present $=0$; absent $=1$ (Fig. 43).

186. Basolateral ridges of abdominal tergites III-V (in Solierius IV-V) [C\&G: 101, mod.; N: 37]: present $=0$; absent $=1$ (Fig . 43).

187. Spiracles on abdominal segment I, location [C\&G: 102; L\&N: 17, mod.]: in membrane beside tergum $\mathrm{I}=0$ (Fig. 42); in tergum $\mathrm{I}=1$

188. Spiracles on abdominal segment II, location [C\&G: 104]: in membrane beside tergum II = 0 (Fig. 42); in tergum II = 1 .

189. Intercoxal carina on sterna II and III [C\&G: 105 ; L\&N: 21] : absent $=0$ (Fig. 41); present $=1$.

190. Lateral longitudinal carina on each side of sternum III [C\&G: 106]: absent $=0$ (Fig. 42); present $=1$.

191. Parasclerites of abdominal segment II [C\&G: 108]: present $=0$; absent $=1$ (Fig. 42).

192. Pairs of parasclerites of abdominal segment III [C\&G: 109, mod.]: two $=0$; one $=1$; absent $=2$ (Fig. 42 ).

193. Tergum and sternum of abdominal segment III [C\&G: 109, mod.]: not fused, separated by suture or paratergites $=0$ (Fig. 42); fused to form complete abdominal ring $=1$ [parsimoniously uninformative and deactivated].

194. Pairs of parasclerites of abdominal segments IV-VI: two $=$ $0 ;$ one $=1$; absent $=2$ (Fig. 42 )

195. Tergum and sternum of abdominal segments IV-VI [C\&G: 110; S\&N: 5, mod.]: not fused, separated by suture or paratergites $=0$ (Fig. 42); fused to form complete abdominal ring $=1$ [parsimoniously uninformative and deactivated].

196. Pairs of parasclerites of abdominal segment VII [C\&G: 111, mod.; S\&N: 53, mod.]: two, longitudinally separated $=$ 0 ; two, transversely or obliquely separated $=1$; one $=2$; absent, terga and sterna articulated or fused at base $=3$ (Fig. 42).

197. Defensive (odoriferous) glands near abdominal apex [S\&N: 56, mod.; C\&G: 111, mod.]: absent $=0$ (Fig. 41); present $=1$.

198. Structure of defensive (odoriferous) glands near abdominal apex [S\&N: 56, mod.; C\&G: 111, mod.] (not illustrated): paired eversible gland reservoirs between terga VIII and IX = 0 ; paired noneversible gland reservoirs at anterior margin $\mathrm{T}$ IX $=1$; paired noneversible pygidial glands opening into rectum $=2$; unpaired gland reservoir opening externally near anus $=3$; unpaired gland reservoir opening at anterior margin $\mathrm{S}$ VIII $=4$

199. Stridulatory file of lateral surface of abdominal tergite IX [C\&G: 113; N: 43]: absent $=0$ (Fig. 48); present $=1$.

200. Genital segment eversibility: eversible to some extent (allowed by connecting membrane to VIII) $=0$ (Fig. 41); not eversible (dorsum tightly connected to underside of T VIII) = 1.

201. Tergite IX in male, whether divided or not [C\&G: 114; L\&N: 25, mod.]: divided longitudinally $=0$; entire, not divided $=1$ (Fig. 48).
202. Tergite IX in male, whether fused with tergite $X$ or not [C\&G: 114; L\&N: 25, mod.]: not fused with tergite $\mathrm{X}=0$ (Fig. 48); fused with tergite $\mathrm{X}=1$

203. Apex of sternum IX in male [C\&G: 116]: not acutely produced (truncate, emarginate or obtusely angulate) $=0$ (Fig. 46); acutely produced, not bilobed (acuminate, or with median spiniform process) $=1$; acutely produced, bilobed $=2$.

204. Aedeagus, "basal bulb" [N\&T: 101]: without "basal bulb", with large basal median foramen $=0$; with "basal bulb", with small subbasal median foramen $=1$ (Fig. 49).

205. Aedeagus, position of median foramen in repose ("parameral" side) [S\&N: 67; C\&G: 117, mod.] (not illustrated): dorsal $=0$; ventral $=1$; left lateral $=2$; right lateral $=$ 3.

206. Tergite IX in females [C\&G: 119; L\&N: 26, mod.]: separate from tergite $X=0$ (Fig. 56); fused with tergite $X=1$.

207. Lateral parts of tergite IX in female [C\&G: 119 ; L\&N: 26 , mod.]: completely separated by tergite $\mathrm{X}$ or connected by threadlike strip $=0$; connected by bridge at least $10 \%$ tergal length $=1$ (Fig. 56).

208. Female intergonopodal sclerite [C\&G: 120; N: 52]: present $=0$; absent $=1$ (Fig. 57).

209. Gonocoxites I and II [C\&G: 121, mod.; L\&N: 28, mod; S\&N: 63, mod.]: distinctly separated by membrane $=0$ (Fig. 57); fused $=1$.

210. Gonocoxites II (or gonocoxite if only 1) [C\&G: 121, mod.; L\&N: 28, mod.; S\&N: 63, mod.]: separate $=0$ (Fig. 57); fused to one another $=1$.

211. Gonostyle [C\&G: 122; L\&N: 27]: present $=0$; absent $=1$ (Fig. 57).

APPEndix 2. Label data and depository information (FMNH except $\mathrm{CNC}$ as noted) for the larvae used for scoring morphological characters for the phylogenetic analysis of the Staphylinine Group of rove-beetle subfamilies (Coleoptera: Staphylinidae).

Leiodidae: Neopelatops n. sp. 1, Australia, New South Wales, Wilsons Valley, 21.ii.1993, A. Newton \& M. Thayer. Agyrtidae: Necrophilus hydrophiloides Guérin-Méneville, 1835, USA, Oregon, Polk Co., 9.i.1981, P. Johnson. Silphidae: Thanatophilus micans (Fabricius, 1794), Kenya, Mt. Elgon, x. 2001, V.Grebennikov, CNC; Necrodes surinamensis (Fabricius, 1775), USA, Maine, Somerset Co., 14.vi.1976, L.R. Davis; Nicrophorus orbicollis Say, 1825, Canada, Ontario, Markham 12.vi.1979, R.S. Anderson. Apateticinae: Nodynus leucofasciatus Lewis, 1879, Japan, Aomori Prefecture, Hachinohe, 2.vi.1957, A. Fukuda. Trigonurinae: Trigonurus caelatus LeConte, 1874, USA, California, Mariposa Co., 18.v.1976, A. Newton \& M. Thayer. Omaliinae: Acrolocha newtoni Thayer, 2003, Mexico, Jalisco, 20.-21.ix.1973, A. Newton. Tachyporinae: Tachinus luridus Erichson, 1840, USA, Illinois, Cook Co., 13.v.1991 A. Newton \& M. Thayer. Piestinae: Piestus pygmaeus Laporte, 1835, Mexico, Veracruz, Balzapote, 7.viii.1976, A. Newton. Oxyporinae: Oxyporus rufipennis LeConte, 1963, USA, Michigan, Berrien Co., 6.vi.1990, A. Newton \& M. Thayer. Scydmaeninae: Palaeostigus bifoveolatus (Boheman, 1851), South Africa, W. Cape Prov., Knysna, 6.viii.2002, V. Grebennikov (CNC); Euconnus sp., Mexico, 3 mi NE Temascaltepec, 14.ix.1973, A. Newton; Stenichnus turbatus Casey, 1897 (see: Wheeler \& Pakaluk, 1983); Scydmaenus sp., Panama, Canal Zone, Madden Preserve, 30.vi.1976, A. Newton; Veraphis sp., USA, California, Fresno Co., Sierra N.F., Tamarack Ridge, 16.v.1976, A. Newton \& M. Thayer; Cephennodes sp., Australia, New South Wales, Lord Howe I., 23.v.1980, S. \& J. Peck. Megalopsidiinae: Megalopinus sp., Mexico, Chiapas, Palenque, 27-29.vii.1983, S. \& J. Peck. Leptotyphlinae: "Mex- 
Leptotyphlinae" g. sp. (see Grebennikov \& Newton, 2008); "ChiLeptotyphlinae" g. sp. (see Grebennikov \& Newton, 2008); “AusLeptotyphlinae" g. sp. (see Grebennikov \& Newton, 2008). Steninae: Stenus sp., Panama, Canal Zone, Barro Colorado Island, 19.ii.1976, A. Newton; Dianous sp., USA, New Hampshire, Coos Co., 31.vii.1982, A. Newton \& M. Thayer. Euaesthetinae: Euaesthetus sp., USA, Massachusetts, Bedford, viii.1975, J.Lawrence; Edaphus sp., Australia, New South Wales, Pole Bridge Road, 2.i.1987, A. Newton \& M. Thayer; Octavius neotropicus Puthz, 1977, Panama, Canal Zone, Barro Colorado Island, 12.ii.1976, A. Newton; Alzadaesthetus sp., Chile, Osorno Province, Parque Nac. Puyehue, 20-25.xii.1982, A. Newton \& M. Thayer. Pseudopsinae: Zalobius spinicollis LeConte, 1874 (see: Grebennikov, 2005); Pseudopsis montoraria Herman, 1975 (see: Grebennikov, 2005); Nanobius serricollis (LeConte, 1875) (see: Grebennikov, 2005). Paederinae: ?Pinophilus sp., Australia, Queensland, Kuranda, 22.vi.1971, Taylor \& Feehan; Achenomorphus corticinus Gravenhorst, 1802, USA, Massachusetts, Middlesex Co., 20.viii.1977, A Newton \& M. Thayer; Hyperomma sp., Australia, Tasmania, Lake Chisholm, 12.i.1993, A. Newton \& M. Thayer. Staphylininae: Arrowinus peckorum Solodovnikov \& Newton, 2005 (see: Solodovnikov \& Newton, 2005); Xanthopygus xanthopygus Nordmann, 1837, Mexico, Oaxaca, Totolapam, 6.ix.1973, A. Newton; Nudobius arizonicus Casey, 1906, USA, Arizona, Navaho Co., 31.vii.1974, K. Stephan \& J. Lawrence; Platydracus maculosus (Gravenhorst, 1802), Canada, Ottawa, iv.1998, V. Grebennikov, (CNC).

APPENDix 3. Label data for the adults (all FMNH) used for scoring morphological characters for the phylogenetic analysis of the Staphylinine Group of rove-beetle subfamilies (Coleoptera: Staphylinidae)

Leiodidae: Neopelatops n. sp. 1, Australia, New South Wales, Dead Horse Gap vic., 19.xii.1986-14.ii.87, A. Newton \& M. Thayer. Agyrtidae: Necrophilus hydrophiloides GuérinMéneville, 1835, USA, California, Belmont [no date or collector]. Silphidae: Thanatophilus micans (Fabricius, 1794), Tanzania, Longido West, 21.ii.1916, Loveridge; Necrodes surinamensis (Fabricius, 1775), USA, Arkansas, Franklin Co., Cherry Bend Cpgd., 18.vi.1972, A. Newton; Nicrophorus orbicollis Say, 1825, USA, Tennessee, $5 \mathrm{mi} \mathrm{S}$ of Gatlinburg, 17.-22.v.1972, A. Newton. Apateticinae: Nodynus leucofasciatus Lewis, 1879, Japan, Ehime Prefecture, Odamiyama, 15.v.1968, S. Hisamatsu. Trigonurinae: Trigonurus caelatus LeConte, 1874, USA, California [no date or collector]. Omaliinae: Acrolocha newtoni Thayer, 2003, Mexico, Jalisco, $19 \mathrm{mi}$ W of Atenquique, 10.-18.ix.1971, A. Newton. Tachyporinae: Tachinus memnonius Gravenhorst, 1802, USA, Arkansas, Polk Co., Queen Wilhelmina St. Pk., 11.-12.x.1974, A. Newton. Piestinae: Siagonium punctatum (LeConte, 1866), Mexico, Nuevo Leon, Cerro Potosi, 28.v.1971, A. Newton. Solieriinae:
Solierius obscurus (Solier, 1849), Chile, Osorno Province, P.N. Puyehue, Anticura, 19.-26.xii.1982, A. Newton \& M. Thayer. Oxyporinae: Oxyporus lateralis Gravenhorst, 1802, USA, Massachusetts, Tyngsboro [no date or collector]. Scydmaeninae: Palaeostigus bifoveolatus (Boheman, 1851), South Africa, W. Cape Prov., Knysna, 30.x.1949, B. Malkin; Euconnus sp., USA, Illinois, Union Co., Little Grand Canyon, 15.x.1995, M. Thayer; Stenichnus sp., USA, New Hampshire, Coos Co., Jefferson Notch, 7.ix.1975, A. Newton \& M. Thayer; Scydmaenus sp., Panama, Madden Lake area, 7.ii.1959, H. Dybas; Veraphis sp., USA, California, Mariposa Co., Yosemite N.P. 19.v.1976, A. Newton \& M. Thayer; Cephennodes sp., Australia, New South Wales, Lord Howe I., 24.v.1980, S. \& J. Peck. Megalopsidiinae: Megalopinus sp., Brazil, Santa Catarina, Nova Teutonia, iv.-v.1977, F. Plaumann. Leptotyphlinae: Idahotyphlus alleni Gusarov, 2003, USA, Idaho, Boise Co., Ten Mile Cpgd., 20.v.1982, A.D. Allen; Eutyphlops sp., Chile, Concepción Province, $8.4 \mathrm{~km} \mathrm{~W}$ of La Florida, 2.i.1983, A. Newton \& M. Thayer; Neotyphlini g. sp., Australia, W. Australia, Walpole N.P., 13.xii.1976, J. Kethley. Steninae: Stenus sp., USA, Massachusetts, Middlesex Co., Bedford, 2.iv.1977, A. Newton \& M. Thayer; Dianous nitidulus LeConte, 1874, USA, New Mexico, Lincoln Co., S. Fork Bonito Creek, 7.vii.1972, A. Newton. Euaesthetinae: Euaesthetus americanus Erichson, 1840, USA, Massachusetts, Middlesex Co., Bedford, 2.iv.1977, A. Newton \& M. Thayer; Edaphus sp., Australia, New South Wales, Dorrigo N.P., Blackbutt Tr., 28.ii-5.iii.1980, A. Newton \& M. Thayer; Octavius neotropicus Puthz, 1977, Panama, Canal Zone, Barro Colorado Island, 4.ii.1976, A. Newton; Alzadaesthetus furcillatus Sáiz, 1972, Chile, Osorno Province, P.N. Puyehue, Anticura, 19.-26.xii.1982, A. Newton \& M. Thayer. Pseudopsinae: Zalobius spinicollis LeConte, 1874, USA, Washington, Pierce Co., Mt. Rainier N.P., 22.vii.1975, A. Newton \& M. Thayer; Pseudopsis montoraria Herman, 1975, USA, California, Amador Co., Peddler Hill, 27.vi.1975, A. Newton; Nanobius serricollis (LeConte, 1875), USA, California, Amador Co., Tiger Creek, 26.vi.1975, A. Newton. Paederinae: Pinophilus latipes Gravenhorst, 1802, USA, Florida, Duval Co., Little Talbot Island St. Pk., 14.iv.1971, A. Newton; Achenomorphus corticinus Gravenhorst, 1802, USA, Arkansas, Newton Co., Lost Valley near Ponca, 23.-24.x.1974, A. Newton; Hyperomma bryophilum Lea, 1923, Austraia, Tasmania, Lower Gordon River, 11.ii.1977, Howard \& Hill. Staphylininae: Arrowinus peckorum Solodovnikov \& Newton, 2005, South Africa, W. Cape Prov., Knysna, 30.x.1949, B. Malkin; Xanthopygus xanthopygus Nordmann, 1837, Mexico, Oaxaca, $5 \mathrm{mi} \mathrm{W}$ of Tequisistlán, 6.ix.1973, A. Newton; Nudobius arizonicus Casey, 1906, USA, Arizona, Apache Co., Chuska Mts, 31.viii.1974, K. Stephan \& J. Lawrence; Platydracus maculosus (Gravenhorst, 1802), USA, New Jersey, Cape May Co., Pierce's Point, 1.-6.ix.1969, A. Newton. 